\title{
Electron Releasing Effect on the Thermodynamic and Transport Properties of Liquid Mixtures at Various Temperatures
}

\author{
*Muvva Raghavendra ${ }^{\mathrm{a}}$, A. Venkatesulu ${ }^{\mathrm{b}}$, \\ K. Sambasiva Rao ${ }^{\mathrm{c}}, \mathrm{P}$. Venkateswarao ${ }^{\mathrm{d}}$ \\ ${ }^{a}$ Department of Physics, Rayalaseema University, Kurnool-518001, AP, India. \\ ${ }^{b}$ Department of Physics, Govt. First Grade College, Hosakote, Bangalore Rural, Karnataka, -562114, India \\ ${ }^{c}$ Department of Physics, J.K.C.College.Acharya Nagarjuna University, Guntur-522006, AP, India \\ ${ }^{d}$ Department of Chemistry, R.V.R. \& J.C. College. Acharya Nagarjuna University, Guntur-522019, A.P, India \\ Corresponding Author:A. Venkatesulu\& Muvva Raghavendra
}

\begin{abstract}
Densities ( $\rho)$, speeds of sound ( $u$ ), and viscosities $(\eta)$ are reported for binary mixtures of $N, N$-diethyl aniline with 1-alkanols (1-hexanol, 1-heptanol and 1-octanol) over the entire composition range of mole fraction at $T=(303.15-318.15) \mathrm{K}$ and at atmospheric pressure 0.1 MPa. The excess properties such as excess molar volume, excess isentropic compressibility and deviations in viscosity are calculated from the density, speed of sound and viscosity. Excess properties are correlated using the Redlich - Kister equation. The excess partial molar volumes and excess partial molar isentropic compressibilities are calculated for all the binary systems throughout the composition range and also at infinity dilutions. The results are analyzed in terms of ruptureofhydrogenbonded chainofthedipolar interaction betweensoluteand1- alkanolexceedstheintermolecular interactionthroughdipole-dipoleandhydrogenbonding between $N$, $N$-diethyl anilineand1-alkanolmolecules.The $V^{E}$ results are analyzed in the light of Prigogine-Flory-Patterson theory. Analysis of each of the three contributions viz. interactional, free volume and $P^{*}$ to $V^{E}$ has shown that interactional contribution are positive for all systems, both the free volume effect and $P^{*}$ contribution are negative for all the mixtures.
\end{abstract}

Keywords: Density, speed of sound, viscosity, N, N-diethyl aniline, 1-alkanols, PFP theory

Date of Submission: 05-07-2017

Date of acceptance: 17-07-2017

\section{Introduction}

Thestudyofthermodynamicpropertiesofbinarymixturescontributesto an understanding of the behaviorofdifferentliquidsandtheirfunctionalgroups. This information is very useful in the design of industrialprocessandinthedevelopment oftheoriesfortheliquidstateandpredictivemethods.Excess thermodynamicparametersofdifferentmixturesareusefulinthe studyofmolecularinteractionsand arrangements[1].Forengineeringapplications, liquidmixtures,ratherthan single componentliquidsystemsare usedin processingandproductformulations. The thermodynamicparametersderivedfromthemeasurementof density,speed of soundandviscosityare usefulinunderstandingthenatureandtypeofintermolecular interactionsbetweenthecompoundmolecules

The variations in densities, speeds of sound and other properties derived using them, pertainingto binary mixtures of alcohols with divergent organic liquids which differ in molecular size, shape, chain length and degree of molecular association than that of normal alcohols, is one of the interesting aspect of research in molecular interactions [2]. In the present work, the liquid components selected for the study of molecular interactions are N, N-diethyl aniline and 1-alkanols: 1-hexanol, 1-heptanol and 1-octanol.These solvents are well known organic liquids with a wide range of applications in various fields of chemistry in addition to their use in industries and routine analytical work. N, N-diethyl aniline is used as a solvent and also in preparation of dyes and various organic products. Alcohols are interesting as they are biologically and industrially important amphiphilic materials and also versatile solvents used in chemical and technological processes and further, they are inexpensive and easily available at high purity [3].

The aim of the present work is to know the effect of carbon chain length and the influence of polarity of the 1-alkanols in the binary blends of N, N-diethyl aniline with 1-alkanols on the excess volume, excess isentropic compressibility and deviation in viscosity values. The present investigation is a continuation of our earlier research [4] on thermodynamic properties of binary liquid mixtures.

A review of the literature has shown that the thermodynamic properties of binary mixtures of $\mathrm{O}$ chlorophenol with aniline and N-alkylanilines [5], 2-methoxyethanol with diethylamine and triethylamine [6], $\mathrm{m}$-cresol with substituted anilines [7] and 2-(2-butoxyethoxy) ethanol with aniline and $\mathrm{N}$-alkylanilines [8] have been investigated. There are no information accessible indicating itemized physical properties such as density, 
speed of sound and viscosity for the binary mixtures of N, N-diethyl aniline with 1-alkanols. Hence, this research work is undertaken pertaining to these binary blends. The data found in this work may be helpful in various industrial processes such as formulation of PVC cements. In this paper we report densities $(\rho)$, speeds of sound $(u)$ and viscosities $(\eta)$ of the binary mixtures of $\mathrm{N}, \mathrm{N}$-diethyl aniline with 1-alkanols (including pure liquids) at different temperatures over the entire composition range. By using these data, various physicochemical parameters, viz., $V^{E}$ (excess molar volume), $\kappa_{s}^{E}$ (excess isentropic compressibility), deviation in viscosity $(\Delta \eta)$, excess Gibbs energy of activation of viscous flow $\left(G^{* E}\right), \bar{V}_{\mathrm{m}, 1}^{{ }^{\circ} \mathrm{E}}, \bar{V}_{\mathrm{m}, 2}{ }_{\mathrm{E}} \mathrm{K} \overline{\mathrm{s}}_{\mathrm{s}, \mathrm{m}, 1}^{\circ}$ and $\bar{K}_{\mathrm{s}, \mathrm{m}, 2}{ }^{\circ} \mathrm{E}$ have been calculated.

\subsection{Materials}

\section{Experimental}

Chemicals used in the present study were N, N-diethyl aniline, 1-hexanol, 1-heptanol and 1-octanol. All the chemicals were purchased from S.D. Fine Chemicals Ltd. N, N- diethyl aniline was dried over potassium hydroxide pellets for several days [9]. All the chemicals were further purified by distillation and fractional distillation under reduced pressure, and only the middle fractions were collected $[9,10]$. Before use, the chemicals were stored over $0.4 \mathrm{~nm}$ molecular sieves for about $72 \mathrm{~h}$ to remove water and degassed. The purity of the liquid samples was checked by gas chromatography. The water contents were determined by Karl-Fischer method. The details of the chemicals and pertaining purification methods were presented in Table 1 .

\subsection{Apparatus and procedure}

All the binary liquid mixtures were prepared by weighing an amount of pure liquids in an electric balance (ER-120A, Afoset) with a precision of $\pm 0.1 \mathrm{mg}$ by syringing each component into air-tight stopper bottles to minimize evaporation losses. The uncertainty of the mole fraction was $\pm 1 \times 10^{-4}$. Thedensitiesofpureliquidsand theirbinarymixturesweremeasured byusing asinglecapillarypycnometer(madeofBorosilglass)

havingabulbcapacityof $\sim 10 \mathrm{~cm}^{3}$.Thecapillarywithgraduatedmarks haduniformboreandcouldbeclosed withawell-fittedcap.Themarks onthe capillarywerecalibrated byusing triplydistilledwater.Theuncertaintyindensitymeasurementwasfoundwithin $\pm 0.2 \times 10^{-3} \mathrm{~g} \cdot \mathrm{cm}^{-3}$. The speed of sound measurements was performed using a commercially available single crystal ultrasonic in terferometer (model F-05) from Mittal Enterprises, New Delhi, India, at $2 \mathrm{MHz}$ frequency at various temperatures. The uncertainty in the measured speed of sound is $\pm 0.5 \%$. The temperatureofthe testliquidsduringthe measurementswas maintained withinanuncertaintyof \pm 0.01 Kinanelectronicallycontrolled thermostaticwaterbath. The interferometer function was tested by obtaining measurements for pure samples of benzene, toluene, chloroform, chlorobenzene and acetone and the measured speeds of sound of these liquids were in good agreement with those reported in the literature [11].The viscosities of pure liquids and their mixtures were determined at atmospheric pressure at $\mathrm{T}=(303.15-318.15) \mathrm{K}$ by using an Ubbelohde viscometer, which was calibrated with benzene, carbon tetrachloride, acetonitrile and doubly distilled water [12]. The Ubbelohde viscometer bulb capacity was $15 \mathrm{ml}$ and the capillary tube had a length of about $90 \mathrm{~mm}$ with $0.5 \mathrm{~mm}$ internal diameter. The viscometer was thoroughly cleaned and perfectly dried, filled with the sample liquid by fitting the viscometer to about $30^{\circ}$ from the vertical and its limbs were closed with Teflon caps to avoid the evaporation. The viscometer was kept in a transparent walled bath with a thermal stability of \pm 0.1 $\mathrm{K}$ for about $20 \mathrm{~min}$ to obtain thermal equilibrium. An electronic digital stopwatch with an uncertainty of \pm 0.01 $\mathrm{s}$ was used for flow time measurements. The experimental uncertainty of viscosity was estimated as $\pm 1.03 \%$ and the uncertainty of temperature $\pm 0.1 \mathrm{~K}$. The purity of all these solvents were compared with the measured densities, speeds of sound and viscosities of the pure liquids with the literature [13-21] and these were enlisted in Table 2.

Experimental datagraphically compared [22-33] and in the givensupplementarymaterial Figs. from $1 \mathrm{~S}$ to $9 \mathrm{~S}$ and also third-order polynomial was used to fit viscosity and speed of sound as a function of concentration, for pure substances and its binary mixture of N,N-diethyl aniline with 1-heptanol, + 1-octanol, were listed in Tables and Figs. 1S, 2S. 10S, 11S and 12S respectively (Supplementary material).

The analysis of 1-hexanol indicated that the literature $\rho$ data [23] are more scattered as compared to our data. It may arise due to experimental procedure because viscosity ' $\eta$ ' was well correlated with our experimental values. The AAD values for ' $u$ ' were found to be less than $0.28 \%$ (Jerie et al [27])to our experimental values may be experimental procedure or chemical purity. The 1-heptanol and 1-octanol speed of sound ' $u$ ' values varies with $0.4 \%$ and $0.35 \%$ (Average Absolute Deviation) with Dzida et al [32] at 303.15K. The deviations may be arising due to experimental procedure. 


\section{Results And Discussion:}

The experimental densities and viscosities for all the binary systems at various compositions were used to calculate the excess thermodynamic functions using following equations:

$$
\begin{gathered}
V^{E} / \mathrm{cm}^{3} \cdot \mathrm{mol}^{-1}=\left[x_{1} M_{1}+x_{2} M_{2}\right] / \rho-\left[x_{1} M_{1} / \rho_{1}+x_{2} M_{2} / \rho_{2}\right] \\
\Delta \eta / m P a \cdot s=\quad \eta-\left(x_{1} \eta_{1}+x_{2} \eta_{2}\right) \\
G^{* E} / J \cdot m o l^{-1}=R T\left[\ln \eta V-\left(x_{1} \ln \eta_{1} V_{1}+x_{2} \ln \eta_{2} V_{2}\right)\right]
\end{gathered}
$$

where $\rho, \eta$ and $V$ are density, viscosity and molar volume of the binary mixture. $x_{l}, M_{1}, \rho_{l}, \eta_{l}, V_{l}$ and $x_{2}, M_{2}$, $\rho_{2}, \eta_{2}, V_{2}$ are the mole fraction, molar mass, density, viscosity and molar volume of pure components 1 and 2 respectively. $R$ is the gas constant and $\mathrm{T}$ is the absolute temperature

The experimental data were used to compute isentropic compressibility $\left(\kappa_{s}\right)$ by using the following relation:

(4)

$$
\kappa_{s}=\left(u^{2} \rho\right)^{-1}
$$

The method used for calculating $\kappa_{s}^{E}$ (Benson - Kiyohara approach) was outlined previously [34].

$\mathrm{V}^{\mathrm{E}}, \kappa_{s}^{E}$ and $\Delta \eta$ values were fitted to a Redlich - Kister [35] polynomial equation,

$$
Y^{\mathrm{E}}=x_{1} x_{2} \sum_{i=0}^{j} A_{i}\left(1-2 x_{1}\right)^{i}
$$

where $Y^{E}$ is the $\mathrm{V}^{\mathrm{E}}, \kappa_{s}^{E}$ and $\Delta \eta$. Values of the coefficients $A_{i}$ were determined by using the method of least squares. The standard deviations $\sigma\left(Y^{E}\right)$ were calculated by using the formula

$$
\sigma\left(Y^{E}\right)=\left[\Sigma\left(Y_{\text {exp }}^{E}-Y_{c a l}^{E}\right)^{2} /(m-n)\right]^{1 / 2}
$$

where $\mathrm{m}$ is the total number of experimental points and $\mathrm{n}$ is the number of parameters. The coefficients, $A_{i}$ and corresponding standard deviation values $(\sigma)$ were presented in Table 5 .

The densities, speeds of sound and viscosities for mixtures of various mole fractions of $\mathrm{N}, \mathrm{N}$-diethyl aniline in 1-alkanols were presented in Tables 3.The excess molar volumes, excess isentropic compressibility, viscosity deviation and excess Gibbs energy of activation of viscous flow at various temperatures were presented in Tables 4. Figs. 1, 2, 3 and 4 show values of $V^{E}, \kappa_{s}^{E}, \Delta \eta$ and $G^{* E}$ as a function of the molar fraction of N, Ndiethyl aniline, respectively.

The volume changes arising due to addition of $\mathrm{N}$, N-diethyl aniline to an alkanol results from several opposing effects [36]. The main volume effects accompanying the addition of $\mathrm{N}, \mathrm{N}$-diethyl aniline to an alkanol result from changes of free volume,disruption of the alkanol structure, and the so-called condensation effect[37] due to restriction of the rotational motion of the alkanol molecule[38]. A perusal of Table 4shows that theexcess molar volume data for the mixtures $\mathrm{N}, \mathrm{N}$-diethyl aniline with 1-alkanols are positive over the entire composition range at all temperatures. In the present mixtures, considerable amounts of positive contributions are expected due todissociation of intermolecular interactions between like molecules is dominant over the heteroassociation interactions between unlike molecules. Similar results have also been reported for N,N-dimethylformamide with n-alkanols [39] and toluene with n-alkanols mixtures [40].

The $\mathrm{V}^{\mathrm{E}}$ values at equimolar concentration of mixtures follow the order:

1-octanol $>1$-heptanol $>1$-hexanol

It indicates thatclustering decreases with increase of chain length of alkanols owing to less proton-donating tendency of higher alkanols. Therefore, heteroassociation effects decrease in the binary mixtures with an increase of chain length of linear alkanols. Hence above order is justified.

The increase of $\mathrm{V}^{\mathrm{E}}$ with increase of temperature suggests the breaking of interactions and aggregates of alkanols and $\mathrm{N}, \mathrm{N}$-diethyl aniline at elevated temperature [36].An examination of data in the Table 4 shows that the excess isentropic compressibility data for all the binary systems are positive over the entire composition range at $\mathrm{T}=(303.15$ to 318.15$) \mathrm{K}$.

The observed values of $\kappa_{s}^{E}$ can be qualitatively explained by considering the factors (i) declustering and breaking of H-bonds in 1-alkanols (ii) repulsive forces due to the electric charge of components, (iii) size and shape of both component molecules along with the effect of the alkyl chain of the 1-alkanols because the hydrophobic character of the 1-alkanol is amplified by an increase in chain length, and consequently, the molecular interactions between 1-alkanols and $\mathrm{N}, \mathrm{N}$-diethyl aniline molecules are weaken. It also suggests that the physical dipole-dipole interactions between 1-alkanol monomers and multimers contribute to increase in free-spaces and these results in decrease in sound velocity and it is reflected in the positive deviation in isentropic compressibilities [41]

Fromthe Fig.2, it is inferred that the positive $\kappa_{s}^{E}$ values increases from 1-octanol to 1-heptanol in their binary blends with $\mathrm{N}, \mathrm{N}$-diethyl aniline. This fact signifies decreasing dipole-dipole interaction due to decreasing proton donating ability with increasing chain length of 1 -alkanols. It also suggests the rupture of hydrogen bonded chain of the dipolar interactions between N,N-diethyl aniline and 1-alkanol exceed the 
intermolecular interaction through dipole-dipole and hydrogen bonding between N,N-diethyl aniline and 1alkanol molecules.

The positive $\kappa_{\mathrm{s}}^{\mathrm{E}}$ values for binary systems follow the order:

1-octanol >1-heptanol>1-hexanol

The order indicates that the strength of interactions between component molecules decreases due to decrease in polarizability of 1 -alkanol molecules $[42,43]$ as the carbon chain increases and also decreases in proper dipole alignment of the components.

According to Kauzman and Eyring [44], the viscosity of a mixture strongly depends on the entropy of mixture, which is related to liquid structure and enthalpy and consequently, to the molecular interactions between the components of the mixture. Vogel and Weiss [45] affirm that mixtures with strong interactions between different molecules $\left(H^{E}<0\right)$ and negative deviations from Raoult's law present positive viscosity deviations $(\Delta \eta>0)$, whereas for mixtures with positive deviations of Raoult's law and without strong specific interactions, the viscosity deviations are negative $(\Delta \eta<0)$.

An examination of curves in Figs. 3 and 4 suggests that the deviation in viscosity $(\Delta \eta)$ and excess Gibbs energy of activation of viscous flow $\left(G^{*}\right)$ for all the binary systems is negative over the entire composition range at different temperatures. The negative values of deviation in viscosity and excess Gibbs free energy of activation of viscous flow for the binary systems investigated suggest that the breaking of the self-associated molecules and weak interactions between unlike molecules, decrease systematically with an increasein chain length of alkanol. With increasing in chain length of alkanol, hydrogen bonding interaction of $\mathrm{N}, \mathrm{N}-$ diethylaniline with 1-hexanol, 1-heptanol and 1-octanol is weaker due to decreased polarizabilityas suggested by Mecke [38].The viscosity deviation values are found to be opposite to the sign of excess molar volumes for all binary mixtures, which is in agreement with the view proposed by Brocos et al [46, 47]

\section{Partial Molar Properties}

The interpretation of excess partial molar properties $\left(\bar{V}_{\mathrm{m}, 1}^{\mathrm{E}}, \bar{V}_{\mathrm{m}, 2}^{\mathrm{E}}, \bar{K}_{\mathrm{s}, \mathrm{m}, 1}^{\mathrm{E}}\right.$ and $\left.\bar{K}_{\mathrm{s}, \mathrm{m}, 2}^{\mathrm{E}}\right)$ and excess partial molar properties at infinite dilution $\left(\bar{V}_{\mathrm{m}, 1}{ }_{\mathrm{E}}, \bar{V}_{\mathrm{m}, 2}{ }_{\mathrm{E}} \bar{K}_{\mathrm{s}, \mathrm{m}, 1}{ }^{\circ}\right.$ and $\left.\bar{K}_{\mathrm{s}, \mathrm{m}, 2}{ }^{\circ}\right)$ of components 2 have previously been described [48].

In general, the negative values of excess partial molar volume component 1 and excess partial molar volume component $2\left(\bar{V}_{m, 1}^{E}, \bar{V}_{m, 2}^{E}, \bar{K}_{\mathrm{s}, \mathrm{m}, 1}^{\mathrm{E}}\right.$ and $\left.\bar{K}_{\mathrm{s}, \mathrm{m}, 2}^{\mathrm{E}}\right)$ values, indicate the presence of significant solute-solvent interactions between unlike molecules, whereas the positive excess partial molar volume component 1 and excess partial molar volume component 2 data indicate presence of solute-solute / solvent-solvent interactions between like molecules in the mixtures $[49,50]$.

A close perusal of Table 6 indicates that the values of $\bar{V}_{\mathrm{m}, 1}^{\mathrm{E}}$ and $\bar{V}_{\mathrm{m}, 2}^{\mathrm{E}}$ are positive for all the binary mixtures over the whole composition range. Positive values may be attributed to the breaking up of self-associated structures of the components of the mixtures is dominant over the effect of H-bonding and dipole-dipole interaction between unlike molecules

From the Table 6 it may be inferred that the values of $\bar{K}_{\mathrm{s}, \mathrm{m}, 1}^{\mathrm{E}}$ and $\bar{K}_{\mathrm{s}, \mathrm{m}, 2}^{\mathrm{E}}$ are positive for all the binary mixtures over the whole composition range. The positive values indicate thattheruptureofhydrogen bondedchainofthedipolarinteraction betweensolute, $N, \quad \mathrm{~N}$-diethyl anilineand1alkanolexceedtheintermolecularinteractionthroughdipole-dipoleandhydrogenbondingbetweenN, N-diethyl aniline and 1-alkanolmolecules.

From the Table 7, it can be seen that the values of $\bar{V}_{\mathrm{m}, 1}^{\circ}$ and $\bar{V}_{\mathrm{m}, 2}{ }_{\mathrm{E}}$ are positive for all the binary mixtures over the whole composition range. The positive $\bar{V}_{\mathrm{m}, 1}^{\circ}$ and $\bar{V}_{\mathrm{m}, 2}^{\circ}$ values indicate that the rupture of three-dimensional hydrogen-bonded networkof 1-alkanol duetotheadditionofsolute,N,N-diethyl anilineisnotcompensatedbytheweakinteractionsbetweenunlike molecules.

It is seen from the Table 7 that the values of $\bar{K}_{\mathrm{s}, \mathrm{m}, 1}^{{ }^{\circ}}$ and $\bar{K}_{\mathrm{s}, \mathrm{m}, 2}{ }^{\circ}$ are positive for all the binary systems at each investigated temperature. The positive values may be due to interruption of dipolar association in the binary mixtures of $\mathrm{N}, \mathrm{N}$-diethyl aniline with 1-alkanols or attributed to weak dipole-dipole interactions between unlike molecules in the mixtures $[51,52]$. 


\section{Prigogine-Flory-Patterson Theory:}

The Prigogine-Flory-Patterson theory considers excess thermodynamic properties of binary mixtures to be the sum of different contributions [53-55]. The excess molar volume can be expressed as: an interactional term which is proportional to the interaction parameter, $\chi_{12}$, a free volume contribution which arises from the dependence of the reduced volume upon the reduced temperature as a result of the differences between the degrees of thermal expansion of the components and an internal pressures and of the reduced volumes of the components

$$
\left.\frac{V^{E}}{x_{1} V_{1}^{*}+x_{2} V_{2}^{*}}=\frac{\left(\tilde{V}^{1 / 3}-1\right) \tilde{V}^{2 / 3}}{\left[(4 / 3) \tilde{V}^{-1 / 3}-1\right]} \Psi_{1} \theta_{2}\left(\frac{\chi_{12}}{P_{1}^{*}}\right) \text { int.contribution }\right)-\frac{\left(V_{1}-V_{2}\right)^{2}\left[(14 / 9) \tilde{V}^{-1 / 3}-1\right] \Psi_{1} \Psi_{2}}{\left[(4 / 3) \tilde{V}^{-1 / 3}-1\right) \tilde{V}}
$$

(fv.contribution) $+\frac{\left(\tilde{V}_{1}-\tilde{V}_{2}\right)\left(P_{1}^{*}-P_{2}^{*}\right)}{P_{1}^{*} \Psi_{2}+P_{2}^{*} \Psi_{1}} \Psi_{1} \Psi_{2}\left(P^{*}\right.$ contribution)

The reduced volume of pure component $\tilde{V}_{i}$ was calculated from the isobaric thermal expansively $\alpha_{i}$ by equation:

$$
\tilde{V}_{i}=\left(\frac{1+\left(\frac{4}{3}\right) \alpha_{i} T}{1+\alpha_{i} T}\right)
$$

The $\tilde{V}$ of mixture was approximated in equation (8) by

$\tilde{V}=\Psi_{1} \tilde{V}_{1}+\Psi_{2} \tilde{V}_{2}$

The molecular contact energy fraction of components $\Psi_{1}$ is given by

$\Psi_{1}=1-\Psi_{2}=\frac{\phi_{1} P_{1}^{*}}{\phi_{1} P_{1}^{*}+\phi_{2} P_{2}^{*}}$

The characteristic volume is $V_{i}^{*}=V_{i}^{*} / \tilde{V}_{i}$ and the characteristic pressure is given by

$$
P_{i}^{*}=\frac{T V_{i}^{2} \alpha_{i}}{\kappa_{T i}}
$$

where $\kappa_{T i}$ is the isothermal compressibility of pure component $i$.

The hard-core volume fractions of the components 1and $2\left(\phi_{1}\right.$ and $\left.\phi_{2}\right)$ are defined by

$\phi_{1}=1-\phi_{2}=\frac{x_{1} V_{1}^{*}}{x_{1} V_{1}^{*}+x_{2} V_{2}^{*}}$

The $\kappa_{T}$ values were calculated from the following expression,

$\kappa_{T}=\kappa_{S}+\frac{T V \alpha^{2}}{C_{P}}$

The $\chi_{12}$ parameter required for the calculation of $V^{E}$ using Flory-Patterson theory was derived by fitting the $V^{E}$ expression to the experimental equimolar value of $V^{E}$ for each system investigated. The calculated equimolar values of the three contributions together with the $\chi_{12}$ parameter for each system were listed in Table 8.An analysis of each of the three contributions to $V^{E}$ showed that the interactional contribution was positive for all systems, the free volume contribution was negative for all the mixtures and $\mathrm{P}^{*}$ contribution was positive for all the mixtures except 1-octanol which had a negative internal pressure term. It is clear from Table 8 that the dominant role is played by the interactional contribution and this is the main parameter for deciding the sign and magnitude of excess volumes for $\mathrm{N}, \mathrm{N}$-diethyl aniline + 1-alkanols.

\section{Conclusion}

This paper reports experimental data of densities, speeds of sound and viscosities of binary blends of $\mathrm{N}, \mathrm{N}$-diethyl aniline with 1-alkanols (1-hexanol,1-heptanol and1-octanol) binary mixtures over the entire composition range at $\mathrm{T}=(303.15-318.15) \mathrm{K}$ with $5 \mathrm{~K}$ intervals. From the experimental data, various physicochemical parameters, viz., $V_{\mathrm{m}}^{\mathrm{E}}, \kappa_{\mathrm{s}}^{\mathrm{E}}$ and $\Delta \eta$ of the mixtures, the excess partial molar properties at infinite dilution $\left(\bar{V}_{\mathrm{m}, 1}^{{ }_{\mathrm{E}}}, \bar{V}_{\mathrm{m}, 2}{ }_{{ }_{\mathrm{E}}} \bar{K}_{\mathrm{s}, \mathrm{m}, 1}{ }_{\mathrm{E}}\right.$ and $\left.\bar{K}_{\mathrm{s}, \mathrm{m}, 2}\right)$ of components were calculated. The results are analyzed in terms of rupture ofhydrogenbonded chainofthedipolar interaction betweensoluteand1alkanolexceedtheintermolecular interactionthroughdipole-dipoleandhydrogenbonding betweenN,N-diethyl anilineand1-alkanolmolecules. Thisbehaviorischaracteristicfor systemscontaininganassociated component. Moreover, the $V^{E}$ values have been analyzed with Prigogine- Flory-Patterson theory and shown that the interactional contribution is the main factor for positive values of excess molar quantities.

\section{Acknowledgment}

The author(Dr.A. Venkatesulu) expresses his sincere thanks to principal (Dr. Muninarayanappa), Govt.First Grade College, Hosakote, Bangalore for providing facilities to carry out some part of the research work. 


\section{References}

[1] T.S. Banipal, A. Toor, V.K. Rattan, Indian J. Chem. 39A (2000) 809-818

[2] N.V. Sastry, M.K. Valand, J. Phys. Chem. Liq. 37 (1999) 381-394

[3] K.A. Kurnia, B. Ariwahjoedi, M.I. Abdul Mutalib, T. Murugesan, J. Soln. Chem. 40 (2011) 470-480

[4] M. Gowrisankar, A. Venkatesulu, T. Srinivasa Krishna, K. Ravindhranath, J, Chem. Thermodyns. 107 (2017) $104-113$.

[5] R. Palepu, J. Oliver, B. Mackinnom, Can. J. Chem. 63 (1985) 1024-1030.

[6] C.M. Kinart, W.J. Kinart, D. Checinska-Majak and A. Bald, J. Thermal Anal., and Cal., 75 (2004) 347-354

[7] P. Ramamurthy, O. Joan, B. Mackinnon, Can. J. Chem. 63 (1985) 1024 -1030

[8] P. Wiseman, M. Heggie, P. Ramamurthy, Can, J. Chem 70 (1992) 2645-2649

[9] P.S. Rao, M.C.S. Subha, G.N. Swamy, J. Soln. Chem. 22 (1993) 483-487

[10] T.S. Vijaya Lakshmi. P.R. Naidu, J. Chem. Eng. Data. 34 (1989) 413-414

[11] J. Nath, A.P. Dixit, J. Chem. Eng. Data. 29 (1984) 313-316.

[12] M. Das,M.N.Roy,,J.Chem.Eng.Data51,(2006) 2225-2232

[13] R. Palepu, J. Ollver, D. Camphell, J. Chem. Eng. Data 30 355-360 (1985)

[14] M. Kondaiah, D. Sravana Kumar, K. Sreekanth, D. Krishna Rao, J. Chem. Eng. Data 57 352-357 (2012)

[15] V. Pandiyan, S.L. Oswal, P. Vasantharani, Thermochimica Acta 518 (2011) 36-46

[16] T.M. Reid, J.M. Prausnitz, B.E. Poling, The properties of gases and liquids, $4^{\text {th }}$ ed., McGraw Hill New York (1987)

[17] M.S. AlTuwaim,AlkhaldiHaek, S.A. Al-Jimaz, A.A. Mohammad,J.ChemThermodyn. 48 (2012)39-47

[18] Adel S. Al-Jimaz, Jasem A. Al-Kandary, M. Abdul-Haq, Abdul-Latif, Fluid phase equilibria 218 (2004) 247-260

[19] J. Ortega, J.D. Garcia, Can. J. Chem. 66 (1988) $1520-1524$

[20] Adel S. Al-Jimaz, Jasem A. Al-Kandary, M. Abdul-Haq, Abdul-Latif, J. Chem. Eng. Data 52 (2007) $206-214$

[21] B.D. Djordjevic, I.R. Radovic, M.L.J. Kijevcanin,A.Z. Tasica, S.P. Serbanovic, J. Serb. Chem. Soc. 74 (2009) $477-491$

[22] K. Y. Liew, C. E. Seng, B. H, Ng, JSL 21 (1992) $1177-1183$

[23] A. G. Oskoei, N. Safaei, J. Ghasemi, JCED 53 (2008) 343-349

[24] K. Anil Kumar, Ch. Srinivasu IJIRSET 7 (2014) 14880 - 14889

[25] B.E. de Cominges, M. M. Pineiro, L. Mosteiro, T. P. Iglesias, J. L. Legido, M.I. Paz Andrade, J. Chem. Eng. Data 46 (2001) 12061210

[26] MD Pena, G Tardajos, JCT 11 (1979) 441-445.

[27] K. Jerie, A. Baranowski, J. Przybylski, J. Glinski, J Mol Liq 111 (2004) 25-31

[28] A.S. Al-Jimaz, J. A. Al-Kandary, Abdul-Haq M. Abdul-Latif, J. Chem. Eng. Data 52 (2007) 206-214.

[29] S. Matsuo, T. Makita, Int. J. Thermophys., 10 (1989) 833-843

[30] U. Domanska, M. Krolikowska, J. Chem. Eng. Data 55 (2010) 2994-3004

[31] H. Kumar, S. Sharma, J. Sol Chem. 39(7) (2010) 967-986

[32] M. Dzida, J. Chem. Eng. Data, 52 (2007) 521-531

[33] N. V. Sastry, K.V. Mahendra, J. Chem. Eng. Data 41(1996) 1426-1428

[34] G.C. Benson, O. Kiyohara, J. Chem. Thermodyn. 11 (1979) 1061-1067

[35] O. Redlich, A.T. Kister, J. Ind. Eng. Chem. 40 (1948) 345-348

[36] Paez, Contreras, J. Chem. Eng. Data 34 (1989) 455-459

[37] Tereszczanow, G.C. Benson, Fluid Phase equlibria 23 (1985)117-135

[38] R. Mecke, Discuss Faraday Soc., 9 (1950)161-177

[39] A. Ali, A.K. Nain, V.K. Sharma, S. shmad, Acoust. Lett. 24 (2000) 9-16

[40] G.N. Swamy, G. Dharmaraju, G.K. Raman, Can. J. Chem. 58 (1980) 229-230

[41] B. Jacobson, Arkiv Kemi, 2 (1953) 177-210

[42] M. M. Palaiologou, Ioanna E. Molinou, J. Chem. Eng. Data 40 (1995) 880-882

[43] M. M. Palaiologou, J. Chem. Eng. Data 41 (1996) 1036-1039

[44] W. Kauzmann, H. Eyring, J. Am. Chem. Soc. 62 (1940) 3113-3125

[45] Vogel, H.; Weiss, A. J. Phys. Chem. Chem. Phys. 86 (1982) 193-198

[46] P. Brocos, A. Pineiro, R. Bravo, A. Amigo, Phys. Chem. Chem. Phys.5 (2003) 550-557.

[47] A. Pineiro, P. Brocos, A. Amigo, M. Pintos, R. Bravo, Phys. Chem. Liq. 38 (2000) 251- 260

[48] P. Venkateswara Rao, M. Gowrisankar, L. Venkatramana,T. Srinivasa Krishna, K. Ravindhranath, J. Chem. Thermodyns.101 (2016) 92-101

[49] H. Wang, W. Liu, J. Huang, J. Chem. Thermodyn. 36 (2004) 743-752.

[50] B. Hawrylak, K. Gracie, R. Palepu, J. Soln. Chem. 27 (1998) 17-31.

[51] G. Arul, L. Palaniappan, Indian J. Pure Appl. Phys. 43 (2005) 755-758.

[52] A. Rena, C.Clara, Ana, Gomaz marigliona, Horacio, N. Solimo, J. Chem. Eng. Data 51 (2006) 1473-1478

[53] H.T. Van, D. Patterson, J. Soln. Chem. 11 (1982) 793-805.

[54] D. Patterson, G. Delma, discuss Faraday Soc. 49 (1970) 98-105.

[55] I. Prigogine, The Molecular Theory of Solution. North Holland Corp, Amesterdam (1957).

Table 1 List of chemicals with details of supplier, CAS number, Purity and water content

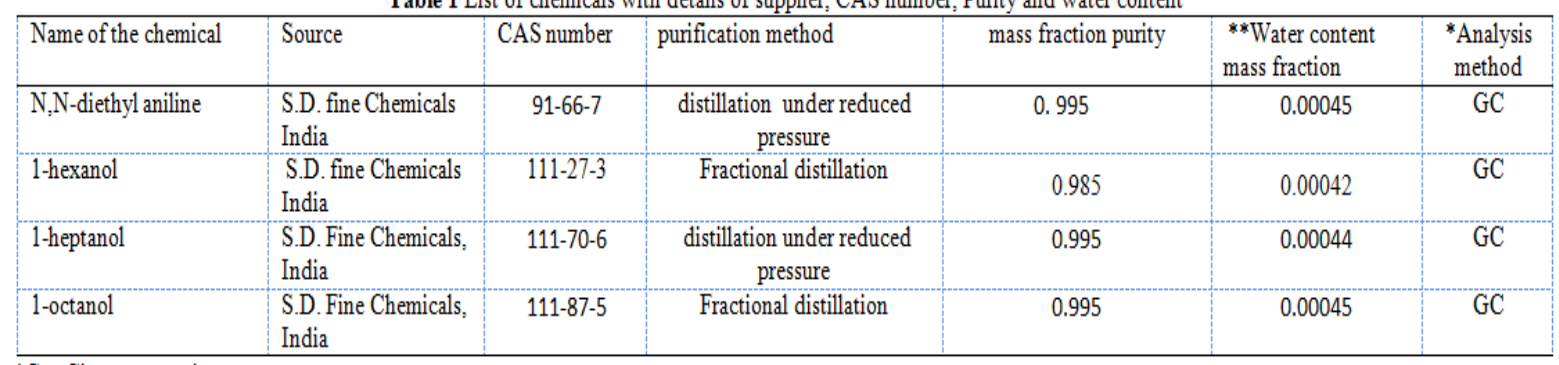

*Gas Chromatography

** Karl-Fischer method 
Electron releasing effect on the thermodynamic and transport properties of liquid mixtures at

\begin{tabular}{|c|c|c|c|c|c|c|c|}
\hline \multirow[t]{2}{*}{ component } & \multicolumn{2}{|c|}{ density $\left(\rho / \mathrm{g} \cdot \mathrm{cm}^{-3}\right)$} & \multicolumn{2}{|c|}{ speed of sound, $\left(\mathrm{u} / \mathrm{m} \cdot \mathrm{s}^{-1}\right)$} & \multirow{2}{*}{$\begin{array}{l}\text { viscosity }(\mathrm{mPa} \cdot \mathrm{s}) \\
\text { experimental }\end{array}$} & \multirow{2}{*}{ literature } & \multirow[t]{2}{*}{$\mathrm{C}_{\mathrm{p}}\left(\mathrm{J} \cdot \mathrm{K}^{-1} \cdot \mathrm{mol}^{-1}\right)$} \\
\hline & experimental & literature & experimental & literature & & & \\
\hline \multicolumn{8}{|l|}{$\mathrm{N}, \mathrm{N}$-diethyl aniline } \\
\hline \multirow{3}{*}{$303.15 \mathrm{~K}$} & $0.9258[4]$ & $0.9259[13]$ & $1432.8[4]$ & $1434.0[15]$ & $1.711[4]$ & $1.709[13]$ & $291.0[16]$ \\
\hline & & $0.9260[14]$ & & & & & \\
\hline & & $0.9261[15]$ & & & & & \\
\hline $308.15 \mathrm{~K}$ & $0.9218[4]$ & $0.9219[13]$ & $1415.2[4]$ & & $1.537[4]$ & $1.534[13]$ & \\
\hline \multirow[t]{3}{*}{$313.15 \mathrm{~K}$} & $0.9179[4]$ & $0.9180[13]$ & $1397.2[4]$ & $1396.0[15]$ & $1.400[4]$ & $1.402[13]$ & $296.0[16]$ \\
\hline & & $0.9177[14]$ & & & & & \\
\hline & & $0.9175[15]$ & & & & & \\
\hline $318.15 \mathrm{~K}$ & $0.9138[4]$ & $0.9139[13]$ & $1378.8[4]$ & & $1.276[4]$ & $1.279[13]$ & \\
\hline \multicolumn{8}{|l|}{ 1-hexanol } \\
\hline $303.15 \mathrm{~K}$ & 0.8122 & $0.81212[17]$ & 1283.4 & $1287.90[20]$ & 3.883 & $3.885[20]$ & $246.52[20]$ \\
\hline $308.15 \mathrm{~K}$ & 0.8081 & $0.80780[19]$ & 1270.2 & $1271.14[20]$ & 3.355 & $3.359[20]$ & $251.47[20]$ \\
\hline $313.15 \mathrm{~K}$ & 0.8043 & $0.80451[17]$ & 1256.9 & $1254.45[20]$ & 2.911 & $2.914[20]$ & $256.48[20]$ \\
\hline $318.15 \mathrm{~K}$ & 0.8002 & $0.80018[18]$ & 1244.2 & & 2.656 & $2.655[18]$ & \\
\hline \multicolumn{8}{|l|}{ 1-heptanol } \\
\hline $303.15 \mathrm{~K}$ & 0.8153 & $0.81529[21]$ & 1315.5 & $1313.58[20]$ & 5.065 & $5.069[20]$ & $275.37[20]$ \\
\hline $308.15 \mathrm{~K}$ & 0.8117 & $0.81174[21]$ & 1298.4 & $1293.86[20]$ & 4.329 & $4.333[20]$ & $289.83[20]$ \\
\hline $313.15 \mathrm{~K}$ & 0.8081 & $0.80816[21]$ & 1280.5 & $1277.15[20]$ & 3.723 & $3.726[20]$ & $295.35[20]$ \\
\hline $318.15 \mathrm{~K}$ & 0.8044 & $0.80439[18]$ & 1261.5 & & 3.446 & $3.447[18]$ & \\
\hline \multicolumn{8}{|l|}{ 1-octanol } \\
\hline $303.15 \mathrm{~K}$ & 0.8183 & $0.81823[21]$ & 1334.9 & $1338.02[20]$ & 6.405 & $6.402[20]$ & $313.60[20]$ \\
\hline $308.15 \mathrm{~K}$ & 0.8147 & $0.81474[21]$ & 1318.7 & $1314.27[20]$ & 5.422 & $5.425[20]$ & $320.12[20]$ \\
\hline $313.15 \mathrm{~K}$ & 0.8101 & $0.81009[21]$ & 1300.0 & $1297.60[20]$ & 4.625 & $4.628[20]$ & $325.98[20]$ \\
\hline $318.15 \mathrm{~K}$ & 0.8055 & $0.80555[18]$ & 1284.9 & & 4.051 & $4.051[18]$ & \\
\hline
\end{tabular}

The standard uncertainties are $\mathrm{u}(\rho)= \pm 0.2 \times 10^{-3} \mathrm{~g} \cdot \mathrm{cm}^{-3}, \mathrm{u}(\mathrm{u})=0.5 \%, \mathrm{u}(\eta)= \pm 1.03 \%, \mathrm{u}(\mathrm{T})=0.01 \mathrm{~K}$ for density and speed of sound, $\mathrm{u}(\mathrm{T})=0.1 \mathrm{~K}$ for viscosity and $\mathrm{u}(\mathrm{p})=$ $1 \mathrm{kPa}$

Table3; Density $(\rho)$, Viscosity $(\eta)$ and speed of sound $(u)$ of binary liquid mixtures of NNN-diethylaniline with 1-hexanol,1-heptanol and 1-octanol at $\mathrm{T}=(303.15$ to

\begin{tabular}{|c|c|c|c|c|c|c|c|c|c|c|c|c|}
\hline \multirow{2}{*}{\begin{tabular}{c}
$x_{1}$ \\
\hdashline $\begin{array}{c}\mathrm{N}, \mathrm{N}- \\
\text { diethylaniline }\end{array}$
\end{tabular}} & \multicolumn{4}{|c|}{ density $\left(\rho / g \mathrm{~cm}^{-3}\right)$} & \multicolumn{4}{|c|}{ viscosity $(\eta / \mathrm{mPa} \cdot \mathrm{s})$} & \multicolumn{4}{|c|}{ speed of sound $\left(\mathrm{u} / \mathrm{m} \cdot \mathrm{s}^{-2}\right)$} \\
\hline & $303.15 \mathrm{~K}$ & $308.15 \mathrm{~K}$ & $313.15 \mathrm{~K}$ & $318.15 \mathrm{~K}$ & $303.15 \mathrm{~K}$ & $308.15 \mathrm{~K}$ & $313.15 \mathrm{~K}$ & $318.15 \mathrm{~K}$ & $303.15 \mathrm{~K}$ & $308.15 \mathrm{~K}$ & $313.15 \mathrm{~K}$ & $318.15 \mathrm{~K}$ \\
\hline \multicolumn{13}{|c|}{$\mathrm{N}, \mathrm{N}$-diethylaniline $(1)+1$-hexanol (2) } \\
\hline 0.0000 & 0.8122 & 0.8081 & 0.8043 & 0.8002 & 3.883 & 3.355 & 2.911 & 2.656 & 1283.4 & 1270.2 & 1256.9 & 1244.2 \\
\hline 0.1057 & 0.8245 & 0.8202 & 0.8167 & 0.8124 & 3.391 & 2.850 & 2.403 & 2.105 & 1293.7 & 1278.4 & 1265.1 & 1252.4 \\
\hline 0.1952 & 0.8348 & 0.8306 & 0.8270 & 0.8227 & 3.041 & 2.524 & 2.096 & 1.801 & 1302.6 & 1287.2 & 1273.6 & 1260.3 \\
\hline 0.3004 & 0.8469 & 0.8427 & 0.8391 & 0.8348 & 2.695 & 2.226 & 1.835 & 1.569 & 1314.3 & 1298.8 & 1284.7 & 1270.8 \\
\hline 0.4021 & 0.8585 & 0.8543 & 0.8507 & 0.8464 & 2.423 & 1.997 & 1.652 & 1.421 & 1326.8 & 1311.2 & 1296.7 & 1282.1 \\
\hline 0.5011 & 0.8698 & 0.8656 & 0.8619 & 0.8577 & 2.207 & 1.814 & 1.518 & 1.314 & 1340.3 & 1324.6 & 1309.5 & 1294.1 \\
\hline 0.6117 & 0.8823 & 0.8782 & 0.8744 & 0.8702 & 2.014 & 1.667 & 1.405 & 1.218 & 1356.8 & 1340.9 & 1325.3 & 1308.9 \\
\hline 0.7135 & 0.8938 & 0.8897 & 0.8859 & 0.8817 & 1.879 & 1.577 & 1.332 & 1.151 & 1373.7 & 1357.7 & 1341.3 & 1324.0 \\
\hline 0.8163 & 0.9053 & 0.9012 & 0.8974 & 0.8932 & 1.780 & 1.525 & 1.297 & 1.119 & 1392.6 & 1376.4 & 1359.3 & 1341.0 \\
\hline 0.9045 & 0.9152 & 0.9111 & 0.9073 & 0.9031 & 1.725 & 1.501 & 1.313 & 1.148 & 1410.5 & 1394.2 & 1376.7 & 1357.5 \\
\hline 1.0000 & 0.9258 & 0.9218 & 0.9179 & 0.9138 & 1.711 & 1.537 & 1.400 & 1.276 & 1432.8 & 1415.2 & 1397.2 & 1378.8 \\
\hline \multicolumn{13}{|c|}{ N,N-diethylaniline (1) + 1-heptanol (2) } \\
\hline 0.0000 & 0.8153 & 0.8117 & 0.8081 & 0.8044 & 5.054 & 4.337 & 3.735 & 3.407 & 1315.5 & 1298.4 & 1280.5 & 1261.5 \\
\hline 0.1216 & 0.8276 & 0.8240 & 0.8203 & 0.8165 & 4.250 & 3.658 & 3.122 & 2.671 & 1322.4 & 1305.9 & .1286 .1 & 1267.9 \\
\hline 0.2426 & 0.8401 & 0.8364 & 0.8327 & 0.8289 & 3.593 & 3.095 & 2.622 & 2.129 & 1330.9 & 1314.5 & 1294.8 & 1276.5 \\
\hline 0.3349 & 0.8498 & 0.8461 & 0.8424 & 0.8385 & 3.178 & 2.735 & 2.308 & 1.826 & 1338.6 & 1322.2 & 1302.7 & 1284.2 \\
\hline 0.4641 & 0.8638 & 0.8600 & 0.8563 & 0.8523 & 2.706 & 2.323 & 1.960 & 1.535 & 1351.1 & 1334.7 & 1315.4 & 1296.6 \\
\hline 0.5612 & 0.8745 & 0.8707 & 0.8669 & 0.8629 & 2.425 & 2.079 & 1.760 & 1.398 & 1361.9 & 1345.5 & 1326.3 & 1307.2 \\
\hline 0.6524 & 0.8848 & 0.8809 & 0.8771 & 0.8731 & 2.210 & 1.895 & 1.617 & $\begin{array}{r}1.319 \\
\end{array}$ & 1373.2 & 1356.6 & 1337.6 & 1318.4 \\
\hline 0.7356 & 0.8943 & 0.8904 & 0.8866 & 0.8826 & 2.049 & 1.763 & 1.520 & 1.278 & 1384.8 & 1368.4 & 1349.4 & 1329.9 \\
\hline 0.8144 & 0.9035 & 0.8996 & 0.8957 & 0.8917 & 1.923 & 1.665 & 1.455 & 1.257 & 1397.1 & 1380.6 & 1361.8 & 1342.0 \\
\hline 0.9141 & 0.9154 & 0.9114 & 0.9075 & 0.9034 & 1.792 & 1.577 & 1.405 & 1.243 & 1414.5 & 1398.1 & 1379.6 & 1359.6 \\
\hline 1.0000 & $0.9258]$ & $0.9218]$ & $0.9179]$ & 0.9138 & 5.065 & 4.329 & 3.723 & 3.446 & 1432.8 & 1415.2 & 1397.2 & 1378.8 \\
\hline \multicolumn{13}{|c|}{ N,N-diethylaniline (1) + l-octanol (2) } \\
\hline 0.0000 & 0.8183 & 0.8147 & 0.8101 & 0.8055 & 6.392 & 5.388 & 4.585 & 4.011 & 1334.7 & 1318.0 & 1298.8 & 1284.3 \\
\hline 0.1141 & 0.8284 & 0.8248 & 0.8202 & 0.8157 & 5.389 & 4.420 & 3.684 & 3.135 & 1339.5 & 1321.5 & 1301.4 & 1288.6 \\
\hline 0.2548 & 0.8415 & 0.8379 & 0.8334 & 0.8289 & 4.382 & 3.490 & 2.854 & 2.356 & 1346.4 & 1328.0 & 1307.3 & 1295.0 \\
\hline 0.3537 & 0.8512 & 0.8476 & 0.8431 & 0.8386 & 3.806 & 2.987 & 2.428 & 1.976 & 1352.5 & 1334.0 & 1313.3 & 1300.5 \\
\hline 0.4726 & 0.8634 & 0.8597 & 0.8553 & 0.8509 & 3.235 & 2.519 & 2.056 & 1.667 & 1361.3 & 1343.3 & 1322.8 & 1308.8 \\
\hline 0.5725 & 0.8742 & 0.8704 & 0.8661 & 0.8617 & 2.842 & 2.221 & 1.837 & 1.503 & 1370.4 & 1352.8 & 1332.7 & 1317.5 \\
\hline 0.6945 & 0.8879 & 0.8840 & 0.8798 & 0.8755 & 2.446 & 1.947 & 1.653 & 1.386 & 1383.9 & 1366.8 & 1347.2 & 1330.5 \\
\hline 0.7795 & 0.8979 & 0.8940 & 0.8899 & 0.8856 & 2.212 & 1.800 & 1.560 & 1.339 & 1395.2 & 1378.2 & 1359.1 & 1341.4 \\
\hline 0.8584 & 0.9076 & 0.9036 & 0.8996 & 0.8953 & 2.016 & 1.684 & 1.487 & 1.305 & 1407.0 & 1390.1 & 1371.3 & 1353.0 \\
\hline 0.9317 & 0.9168 & 0.9129 & 0.9089 & 0.9047 & 1.847 & 1.587 & 1.421 & 1.271 & 1419.5 & 1402.3 & 1383.9 & 1365.2 \\
\hline 1.0000 & 0.9258 & 0.9218 & 0.9179 & 0.9138 & 6.405 & 5.422 & 4.625 & 4.051 & 1432.3 & 1414.8 & 1396.5 & 1377.9 \\
\hline
\end{tabular}

The standard uncertainties are $\left(\mathrm{x}_{\mathrm{l}}\right)=1 \times 10^{-4} \mathrm{u}(\rho)= \pm 0.54 \times 10^{-3} \mathrm{~g} \cdot \mathrm{cm}^{-3}, \mathrm{u}(\mathrm{u})=0.3 \%, \mathrm{u}(\eta)=1.03 \%, \mathrm{u}(\mathrm{T})=0.01 \mathrm{~K}$ for density and speed of sound, $\mathrm{u}(\mathrm{T})=0.1 \mathrm{~K}$ for viscosity and $\mathrm{u}(\mathrm{p})=1 \mathrm{kPa}$ 
Electron releasing effect on the thermodynamic and transport properties of liquid mixtures at

Table 4 Excess molar volume $\left(V^{E}\right)$, excess isentropic compressibility $\left(\kappa_{s}^{E}\right)$, deviation in viscosity $(\Delta \eta)$ and excess Gibbs free energy of activation of viscous flow $\left(G^{* E}\right)$ of liquid mixtures of $\mathrm{N} N$-diethylaniline with 1-hexanol,1-heptanol and1-octanol at $\mathrm{T}=(303.15$ to 318.15$) \mathrm{K}$

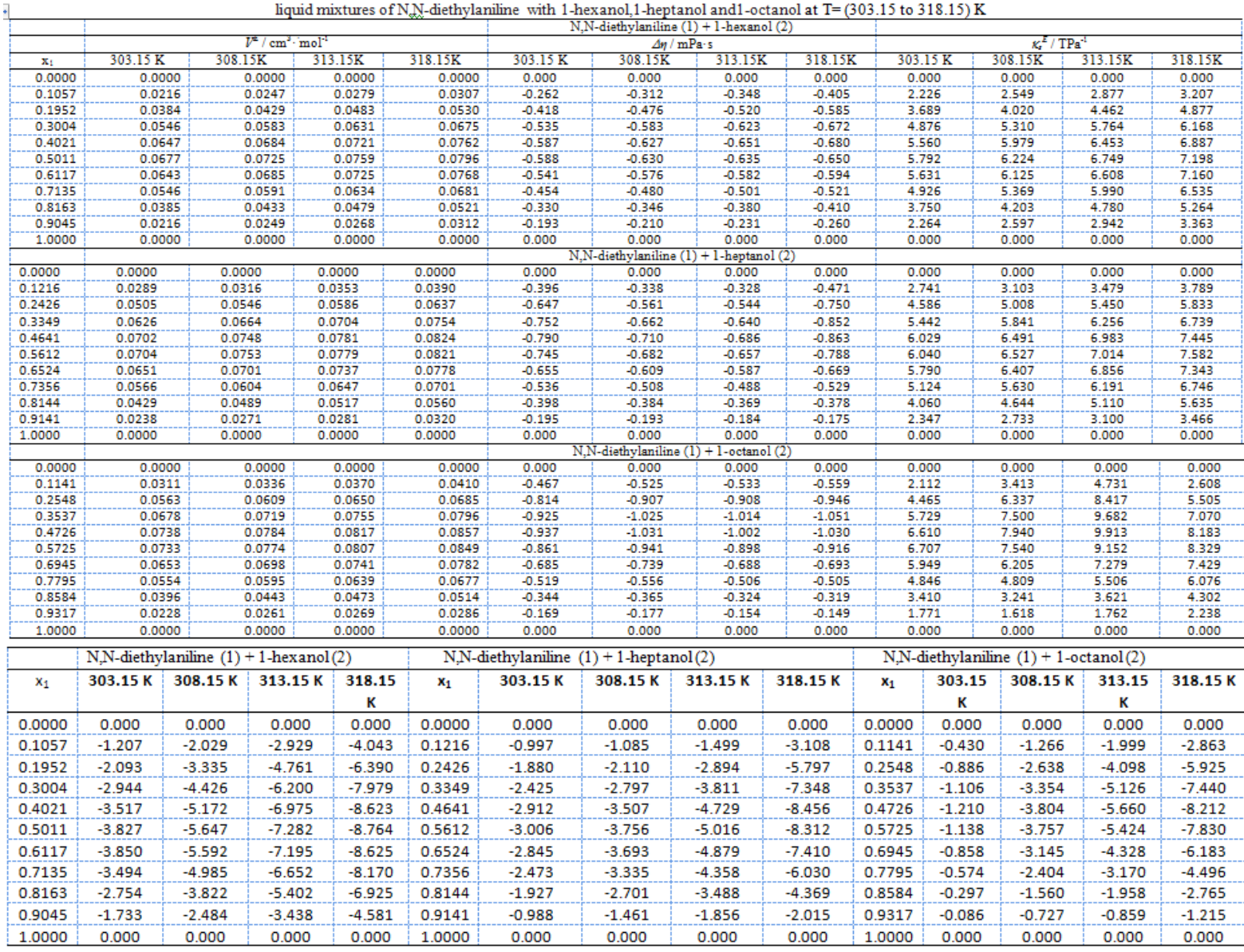

Table 5 Coefficients of Redlich - Kister equation and standard deviation $(\sigma)$ values for liquid mixtures of N, N-diethyl aniline with 1 -alkanols at $\mathrm{T}=(303.15-318.15) \mathrm{K}$

\begin{tabular}{|c|c|c|c|c|c|}
\hline Binary mixtures & Functions & $A_{0}$ & $A_{!}$ & $A_{2}$ & $\sigma$ \\
\hline \multicolumn{6}{|c|}{$303.15 \mathrm{~K}$} \\
\hline \multirow[t]{3}{*}{ N,N-diethylaniline + 1-hexanol } & $V^{2} / \mathrm{cm}^{2} \cdot \mathrm{mol}^{12}$ & 0.272 & 0.013 & -0.051 & 0.001 \\
\hline & $\Delta \eta \mathrm{mPa}=\mathrm{s}$ & -2.351 & 0.362 & -0.237 & 0.003 \\
\hline & $K_{s}^{2} / \mathrm{TPa}^{-1}$ & 23.23 & 1.382 & 2.565 & 0.026 \\
\hline \multirow[t]{3}{*}{$\mathrm{N}, \mathrm{N}$-diethylaniline - 1-heptanol } & $V^{2} 7 \mathrm{~cm}^{3} \cdot \mathrm{mol}^{-12}$ & 0.283 & 0.015 & 0.002 & 0.001 \\
\hline & $\Delta W / \mathrm{mPa} \cdot \mathrm{s}$ & -3.118 & 0.774 & -0.435 & 0.001 \\
\hline & $K_{s}^{2} / \mathrm{TPa}^{-2}$ & 24.32 & 1.857 & 5.201 & 0.054 \\
\hline \multirow[t]{3}{*}{$\mathrm{N}, \mathrm{N}$-diethylaniline+ Y-octanol } & $V=7 \mathrm{~cm}^{-\mathrm{mol}^{-2}}$ & 0.295 & 0.020 & 0.051 & 0.001 \\
\hline & $\Delta \eta \mathrm{mPa} \cdot \mathrm{s}$ & -3.694 & 1.227 & -0.495 & 0.001 \\
\hline & $\mathrm{K}_{\mathrm{s}}^{2} / \mathrm{TPa}^{-\mathrm{F}^{-\cdots}}$ & 26.08 & 1.758 & 6.656 & 0.023 \\
\hline & & & & & \\
\hline \multirow[t]{3}{*}{ N,N-diethylaniline + 1-hexanol } & $V / \mathrm{cm}^{2} \cdot \mathrm{mol}^{-2}$ & 0.288 & 0.015 & -0.020 & 0.001 \\
\hline & $\Delta W \mathrm{mPa} \cdot \mathrm{s}$ & -2.489 & 0.561 & -0.563 & 0.006 \\
\hline & $\mathrm{K}_{s}^{2} / \mathrm{TPa}^{-1}$ & 24.90 & 1.734 & 5.416 & 0.047 \\
\hline \multirow[t]{3}{*}{$\mathrm{N}, \mathrm{N}$-diethylaniline + 1-heptanol } & $V^{2} 7 \mathrm{~cm}^{3} \cdot \mathrm{mol}^{-1}$ & 0.300 & 0.024 & 0.029 & 0.001 \\
\hline & $\Delta \eta / \mathrm{mPa} \cdot \mathrm{s}$ & -3.162 & 0.978 & -0.787 & 0.001 \\
\hline & $\mathrm{K}_{\mathrm{s}}^{\mathrm{z}} / \mathrm{TPa}^{-2}$ & 26.14 & 2.636 & 8.807 & 0.069 \\
\hline \multirow[t]{3}{*}{$\mathrm{N}, \mathrm{N}$-diethylaniline+ Y-octanol } & 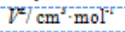 & 0.311 & 0.028 & 0.083 & 0.001 \\
\hline & $\Delta \eta \mathrm{mPa}^{\mathrm{s}}$ & -3.742 & 1.523 & -1.282 & 0.001 \\
\hline & $\mathrm{K}_{s}^{2} / \mathrm{TPa}^{-\mathrm{F}^{-2}}$ & 27.51 & 2.011 & 10.18 & 0.052 \\
\hline \multicolumn{6}{|c|}{$313.15 \mathrm{~K}$} \\
\hline \multirow[t]{3}{*}{ N,N-diethylaniline+ 1-hexanol } & $V^{2} / \mathrm{cm}^{2} \cdot \mathrm{mol}^{2}$ & 0.305 & 0.009 & 0.003 & 0.001 \\
\hline & $\Delta \eta / \mathrm{mPa} \cdot \mathrm{s}$ & -2.543 & 0.649 & -1.005 & 0.009 \\
\hline & $\mathrm{K}_{s}^{2} / \mathrm{TPa}^{-1}$ & 26.94 & 2.249 & 8.256 & 0.024 \\
\hline \multirow[t]{3}{*}{$\mathrm{N}, \mathrm{N}$-diethylaniline + I-heptanol } & $V^{2} 7 \mathrm{~cm}^{3} \cdot \mathrm{mol}^{-1}$ & 0.315 & 0.015 & 0.045 & 0.001 \\
\hline & $\Delta \eta / \mathrm{mPa} \cdot \mathrm{s}$ & -3.212 & 1.214 & -1.125 & 0.001 \\
\hline & $k_{s}^{x} / \mathrm{TPa}^{-1}$ & 27.89 & 3.034 & 12.35 & 0.075 \\
\hline \multirow[t]{3}{*}{$\mathrm{N}, \mathrm{N}$-diethylaniline - $\mathrm{Y}$-octanol } & $V / \mathrm{cm}^{2} \cdot \mathrm{mol}^{-t^{-}}$ & 0.327 & 0.022 & 0.098 & 0.001 \\
\hline & $\Delta \eta \mathrm{mPa} \cdot \mathrm{s}$ & -3.916 & 1.813 & -1.506 & 0.001 \\
\hline & $\mathrm{x}_{\mathrm{s}}^{\mathrm{x}} / \mathrm{TPa}^{-\mathrm{F}^{2}}$ & 29.44 & 2.173 & 11.99 & 0.049 \\
\hline \multicolumn{6}{|c|}{$318.15 \mathrm{~K}$} \\
\hline \multirow[t]{3}{*}{ N,N-diethylaniline + 1-hexanol } & $V / \mathrm{cm}^{2} \cdot \mathrm{mol}^{12}$ & 0.319 & 0.016 & 0.042 & 0.001 \\
\hline & $\Delta W \mathrm{mPa} \cdot \mathrm{s}$ & -2.603 & 0.835 & -1.649 & 0.001 \\
\hline & $\mathrm{K}_{\mathrm{s}}^{2} / \mathrm{TPa}$ & 28.70 & 2.929 & 11.82 & 0.034 \\
\hline \multirow[t]{3}{*}{ N,N-diethylaniline- Y-heptanol } & $\mathrm{V} / \mathrm{cm}^{5} \cdot \mathrm{mol}^{1-t^{-1}}$ & 0.332 & 0.017 & 0.085 & 0.001 \\
\hline & $\Delta \eta \mathrm{mPa} \cdot \mathrm{s}$ & -3.355 & 1.390 & -1.541 & 0.001 \\
\hline & $x_{s}^{2} / \mathrm{TP}^{2}$ & 29.79 & 3.849 & 15.18 & 0.081 \\
\hline \multirow[t]{3}{*}{ N,N-diethylaniline+ 1 -octanol } & $V / \mathrm{cm}^{-\mathrm{mol}^{1 / T}}$ & 0.343 & 0.018 & 0.126 & 0.001 \\
\hline & $\Delta \eta / \mathrm{mPa}=\mathrm{s}$ & -4.018 & 2.018 & -1.519 & 0.001 \\
\hline & $x_{s}^{2} / T \mathrm{~Pa}^{-z^{-a-1}}$ & 31.12 & 4.120 & 15.39 & 0.063 \\
\hline
\end{tabular}


Electron releasing effect on the thermodynamic and transport properties of liquid mixtures at

Table 6: The values $\bar{V}_{m, 1}^{E} \bar{V}_{m, 2}^{E} \bar{K}_{\mathrm{s}, \mathrm{m}, 1}^{\mathrm{E}} \bar{K}_{\mathrm{s}, \mathrm{m}, 2}^{\mathrm{E}}$ of liquid mixtures of N,N-diethyl aniline with 1-alkanols at $\mathrm{T}=(303.15$ - 318.15) K

\begin{tabular}{|c|c|c|c|c|c|c|c|c|c|c|c|c|c|c|c|c|}
\hline \multirow[b]{2}{*}{$x_{i}$} & \multicolumn{2}{|c|}{$303.15 \mathrm{~K}$} & \multicolumn{2}{|l|}{$308.15 \mathrm{~K}$} & \multicolumn{2}{|l|}{$313.15 \mathrm{~K}$} & \multicolumn{2}{|c|}{$318.15 \mathrm{~K}$} & \multicolumn{2}{|l|}{$303.15 \mathrm{~K}$} & \multicolumn{2}{|l|}{$308.15 \mathrm{~K}$} & \multicolumn{2}{|l|}{$313.15 \mathrm{~K}$} & \multicolumn{2}{|l|}{$318.15 \mathrm{~K}$} \\
\hline & $\bar{V}_{m, 1}^{E}$ & $\overline{V_{m, 2}^{E}}$ & $\bar{V}_{m, 1}^{E}$ & $\overline{V_{m, 2}^{E}}$ & $\bar{V}_{m, 1}^{E}$ & $\overline{V_{m, 2}^{E}}$ & $\bar{V}_{m, 1}^{E}$ & $\bar{V}_{m, 2}^{E}$ & $\bar{K}_{s, \mathrm{~m}, 1}^{\mathrm{E}}$ & $\bar{K}_{s, m, 2}^{\mathrm{E}}$ & $\bar{K}_{s, m, 1}^{\mathrm{E}}$ & $\bar{K}_{\mathrm{s}, \mathrm{m}, 2}^{\mathrm{E}}$ & $\bar{K}_{\mathrm{s}, \mathrm{m}, 1}^{\mathrm{E}}$ & $\bar{K}_{\mathrm{s}, \mathrm{m}, 2}^{\mathrm{E}}$ & $\bar{K}_{\mathrm{s}, \mathrm{m}, 1}^{\mathrm{E}}$ & $\bar{K}_{s, m, 2}^{\mathrm{E}}$ \\
\hline \multicolumn{17}{|c|}{ N,N-diethylaniline(1) + 1-hexanol(2) } \\
\hline 0.0000 & 0.234 & 0.000 & 0.283 & 0.000 & 0.318 & 0.000 & 0.377 & 0.000 & 36.65 & 0.000 & 43.52 & 0.000 & 50.77 & 0.000 & 59.07 & 0.000 \\
\hline 0.1057 & 0.205 & 0.001 & 0.230 & 0.003 & 0.249 & 0.004 & 0.278 & 0.006 & 26.86 & 0.530 & 29.97 & 0.722 & 36.77 & 0.921 & 36.82 & 1.166 \\
\hline 0.1952 & 0.173 & 0.007 & 0.187 & 0.010 & 0.199 & 0.013 & 0.213 & 0.017 & 20.48 & 1.651 & 21.89 & 2.134 & 27.64 & 2.640 & 24.80 & 3.254 \\
\hline 0.3004 & 0.134 & 0.021 & 0.140 & 0.026 & 0.148 & 0.029 & 0.153 & 0.036 & 14.70 & 3.541 & 15.26 & 4.295 & 19.42 & 5.096 & 16.17 & 6.040 \\
\hline 0.4021 & 0.096 & 0.043 & 0.100 & 0.048 & 0.107 & 0.052 & 0.109 & 0.059 & 10.46 & 5.827 & 10.86 & 6.660 & 13.47 & 7.566 & 11.42 & 8.576 \\
\hline 0.5011 & 0.064 & 0.071 & 0.068 & 0.076 & 0.073 & 0.079 & 0.076 & 0.084 & 7.275 & 8.45 & 7.772 & 9.189 & 9.106 & 10.03 & 8.617 & 10.87 \\
\hline 0.6117 & 0.036 & 0.110 & 0.039 & 0.113 & 0.044 & 0.116 & 0.047 & 0.118 & 4.526 & 11.89 & 5.141 & 12.49 & 5.483 & 13.20 & 6.329 & 13.74 \\
\hline 0.7135 & 0.017 & 0.147 & 0.020 & 0.151 & 0.024 & 0.155 & 0.027 & 0.158 & 2.587 & 15.71 & 3.163 & 16.40 & 3.045 & 17.20 & 4.336 & 17.71 \\
\hline 0.8163 & 0.006 & 0.181 & 0.008 & 0.190 & 0.010 & 0.201 & 0.012 & 0.209 & 1.140 & 20.43 & 1.510 & 21.83 & 1.307 & 23.32 & 2.286 & 24.51 \\
\hline 0.9045 & 0.001 & 0.201 & 0.002 & 0.222 & 0.003 & 0.245 & 0.003 & 0.265 & 0.331 & 25.45 & 0.469 & 28.32 & 0.373 & 31.25 & 0.764 & 34.10 \\
\hline 1.0000 & 0.000 & 0.208 & 0.000 & 0.252 & 0.000 & 0.298 & 0.000 & 0.346 & 0.000 & 32.21 & 0.000 & 38.09 & 0.000 & 43.93 & 0.000 & 50.28 \\
\hline \multicolumn{17}{|c|}{ N,N-diethylaniline (1) +1 -heptanol(2) } \\
\hline 0.0000 & 0.300 & 0.000 & 0.353 & 0.000 & 0.405 & 0.000 & 0.434 & 0.000 & 42.73 & 0.000 & 51.52 & 0.000 & 59.49 & 0.000 & 67.54 & 0.000 \\
\hline 0.1216 & 0.225 & 0.005 & 0.250 & 0.007 & 0.278 & 0.008 & 0.288 & 0.010 & 28.42 & 0.878 & 31.76 & 1.195 & 39.92 & 1.485 & 38.03 & 1.762 \\
\hline 0.2426 & 0.162 & 0.019 & 0.173 & 0.024 & 0.183 & 0.027 & 0.191 & 0.031 & 19.16 & 2.901 & 20.12 & 3.717 & 26.41 & 4.446 & 22.14 & 5.179 \\
\hline 0.3349 & 0.123 & 0.035 & 0.128 & 0.041 & 0.123 & 0.049 & 0.140 & 0.050 & 14.34 & 4.845 & 14.71 & 5.888 & 19.03 & 6.795 & 15.67 & 7.760 \\
\hline 0.4641 & 0.077 & 0.065 & 0.080 & 0.071 & 0.084 & 0.072 & 0.090 & 0.078 & 9.593 & 7.979 & 10.00 & 8.981 & 11.70 & 9.795 & 10.99 & 10.80 \\
\hline 0.5612 & 0.051 & 0.093 & 0.053 & 0.098 & 0.057 & 0.095 & 0.062 & 0.103 & 6.926 & 10.78 & 7.541 & 11.57 & 7.802 & 12.16 & 8.857 & 13.05 \\
\hline 0.6524 & 0.031 & 0.123 & 0.033 & 0.128 & 0.038 & 0.122 & 0.042 & 0.132 & 4.809 & 14.06 & 5.522 & 14.70 & 5.012 & 15.18 & 6.962 & 16.00 \\
\hline 0.7356 & 0.018 & 0.153 & 0.020 & 0.159 & 0.024 & 0.152 & 0.026 & 0.167 & 3.111 & 17.93 & 3.758 & 18.73 & 3.031 & 19.44 & 5.027 & 20.45 \\
\hline 0.8144 & 0.009 & 0.185 & 0.010 & 0.194 & 0.011 & 0.201 & 0.014 & 0.213 & 1.723 & 22.74 & 2.178 & 24.23 & 1.584 & 25.72 & 3.055 & 27.33 \\
\hline 0.9141 & 0.002 & 0.228 & 0.002 & 0.248 & 0.004 & 0.260 & 0.003 & 0.296 & 0.431 & 31.11 & 0.574 & 34.68 & 0.373 & 38.46 & 0.844 & 41.84 \\
\hline 1.0000 & 0.000 & 0.269 & 0.000 & 0.305 & 0.000 & 0.361 & 0.000 & 0.400 & 0.000 & 41.08 & 0.000 & 48.09 & 0.000 & 55.53 & 0.000 & 61.75 \\
\hline \multicolumn{17}{|c|}{ N,N-diethylaniline $(1)+1-0$ ctanol $(2)$} \\
\hline 0.0000 & 0.366 & 0.000 & 0.422 & 0.000 & 0.447 & 0.000 & 0.487 & 0.000 & 47.43 & 0.000 & 54.98 & 0.000 & 60.13 & 0.000 & 69.65 & 0.000 \\
\hline 0.1141 & 0.257 & 0.007 & 0.283 & 0.009 & 0.298 & 0.009 & 0.318 & 0.011 & 32.20 & 0.871 & 35.00 & 1.129 & 41.99 & 1.274 & 41.26 & 1.591 \\
\hline 0.2548 & 0.163 & 0.027 & 0.172 & 0.033 & 0.181 & 0.035 & 0.190 & 0.038 & 20.67 & 3.403 & 21.20 & 4.130 & 26.57 & 4.570 & 22.88 & 5.555 \\
\hline 0.3537 & 0.117 & 0.046 & 0.121 & 0.053 & 0.128 & 0.056 & 0.134 & 0.060 & 15.56 & 5.620 & 15.81 & 6.455 & 19.03 & 7.018 & 16.54 & 8.279 \\
\hline 0.4726 & 0.076 & 0.072 & 0.078 & 0.079 & 0.084 & 0.081 & 0.089 & 0.084 & 11.19 & 8.681 & 11.70 & 9.323 & 12.41 & 9.912 & 12.42 & 11.13 \\
\hline 0.5725 & 0.051 & 0.098 & 0.053 & 0.102 & 0.058 & 0.105 & 0.063 & 0.107 & 8.266 & 11.89 & 9.048 & 12.24 & 8.288 & 12.83 & 10.01 & 13.78 \\
\hline 0.6945 & 0.027 & 0.136 & 0.030 & 0.140 & 0.033 & 0.145 & 0.037 & 0.148 & 5.079 & 17.46 & 5.916 & 17.74 & 4.495 & 18.56 & 6.950 & 19.19 \\
\hline 0.7795 & 0.015 & 0.172 & 0.017 & 0.178 & 0.019 & 0.186 & 0.022 & 0.193 & 3.055 & 23.17 & 3.704 & 24.01 & 2.498 & 25.36 & 4.518 & 26.10 \\
\hline 0.8584 & 0.007 & 0.215 & 0.008 & 0.227 & 0.009 & 0.242 & 0.010 & 0.257 & 1.446 & 30.52 & 1.812 & 32.68 & 1.108 & 35.00 & 2.277 & 36.40 \\
\hline 0.9317 & 0.002 & 0.266 & 0.002 & 0.289 & 0.002 & 0.313 & 0.003 & 0.342 & 0.383 & 39.71 & 0.492 & 44.11 & 0.278 & 47.92 & 0.633 & 50.68 \\
\hline 1.0000 & 0.000 & 0.325 & 0.000 & 0.366 & 0.000 & 0.403 & 0.000 & 0.450 & 0.000 & 50.88 & 0.000 & 58.56 & 0.000 & 64.42 & 0.000 & 69.37 \\
\hline
\end{tabular}

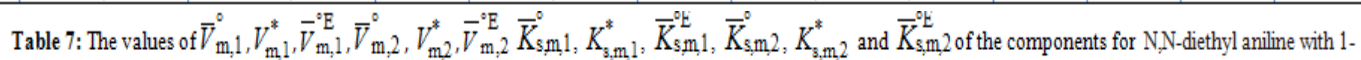
alkanols of binary mixtures at $\mathrm{T}=(303.15-318.15) \mathrm{K}$

\begin{tabular}{|c|c|c|c|c|c|c|c|c|c|c|c|c|}
\hline $\mathrm{T} / \mathrm{K}$ & $\bar{V}_{\mathrm{m}, 1}^{0}$ & $V_{\mathrm{m}, 1}^{*}$ & $\bar{V}_{\mathrm{m}, 1}^{\circ} \mathrm{E}$ & $\bar{V}_{\mathrm{m}, 2}^{0}$ & $V_{\mathrm{m} 2}^{*}$ & $\bar{V}_{\mathrm{m}, 2}^{\circ} \mathrm{E}$ & $\bar{K}_{\text {sm, } 1}^{0}$ & $K_{s, m, 1}^{*}$ & $\bar{K}_{\mathrm{sm}, 1}^{\mathrm{E}}$ & $\bar{K}_{s, m, 2}^{0}$ & $K_{s, m, 2}^{*}$ & $\bar{K}_{s, m, 2}^{\circ E}$ \\
\hline & \multicolumn{6}{|c|}{$\left(\mathrm{cm}^{3} \cdot \mathrm{mol}^{-1}\right)$} & \multicolumn{6}{|c|}{$\mathrm{TPa}^{-1}$} \\
\hline \multicolumn{13}{|c|}{ No-diethylaniline (1) +1-hexanol (2) } \\
\hline 308.15 & 131.75 & 131.47 & 0.283 & 126.72 & 126.47 & 0.252 & 50.63 & 7.113 & 43.52 & 47.81 & 9.718 & 38.09 \\
\hline 313.15 & 132.35 & 132.03 & 0.318 & 127.30 & 127.00 & 0.298 & 58.13 & 7.360 & 50.77 & 53.93 & 10.00 & 43.93 \\
\hline 318.15 & 133.00 & 132.62 & 0.377 & 128.03 & 127.69 & 0.346 & 66.72 & 7.643 & 59.07 & 60.58 & 10.30 & 50.28 \\
\hline 303.15 & 131.20 & 130.90 & 0.300 & 142.80 & 142.53 & 0.269 & 49.63 & 6.895 & 42.73 & 51.18 & 10.10 & 41.08 \\
\hline 308.15 & 131.82 & 131.47 & 0.353 & 143.46 & 143.15 & 0.306 & 58.63 & 7.113 & 51.52 & 58.53 & 10.45 & 48.09 \\
\hline 313.15 & 132.40 & 132.03 & 0.375 & 144.13 & 143.79 & 0.346 & 66.85 & 7.360 & 59.49 & 66.40 & 10.87 & 55.53 \\
\hline 318.15 & 133.06 & 132.62 & 0.434 & 144.86 & 144.46 & 0.400 & 75.19 & 7.643 & 67.54 & 73.04 & 11.29 & 61.75 \\
\hline \multicolumn{13}{|c|}{ N,N-diethylaniline (1) +1-octanol (2) } \\
\hline 303.15 & 131.27 & 130.90 & 0.366 & 159.48 & 159.16 & 0.325 & 54.33 & 6.895 & 47.43 & 61.79 & 10.91 & 50.88 \\
\hline
\end{tabular}

Table 8: PFP interaction parameter, $\chi_{12}$ and calculated values of the three contributions from the PFP theory with experimental excess molar volumes at $x_{1}=0.5$ at $303.15 \mathrm{~K}$

\begin{tabular}{|c|c|c|c|c|c|c|c|}
\hline \multirow[b]{2}{*}{ Binary mixtures } & \multirow[b]{2}{*}{$\chi_{12}\left(10^{6}\right)$} & \multicolumn{3}{|c|}{ Calculated contributions } & \multicolumn{2}{|c|}{$\mathrm{V}_{m}^{E}(x=0.5) \mathrm{cm}^{3} \cdot \mathrm{mol}^{-1}$} & \multirow[b]{2}{*}{$\delta / \mathrm{cm}^{3} \cdot \mathrm{mol}^{-1}$} \\
\hline & & $\begin{array}{l}\text { Interactional(1 } \\
\left.0^{-8}\right)\end{array}$ & Free volume & P* effect & EXP & PFP & \\
\hline $\mathrm{N}, \mathrm{N}$-diethylaniline-1-hexanol & 13.70 & 1.585 & -0.0274 & -0.1219 & 0.0679 & 0.0679 & 0.0000 \\
\hline N,N-diethylaniline+1-heptanol & 6.948 & 1.617 & -0.0014 & -0.0403 & 0.0710 & 0.0707 & 0.0003 \\
\hline N,N-diethylaniline+1-octanol & 6.406 & 1.639 & -0.0010 & -0.0303 & 0.0741 & 0.0737 & 0.0004 \\
\hline
\end{tabular}




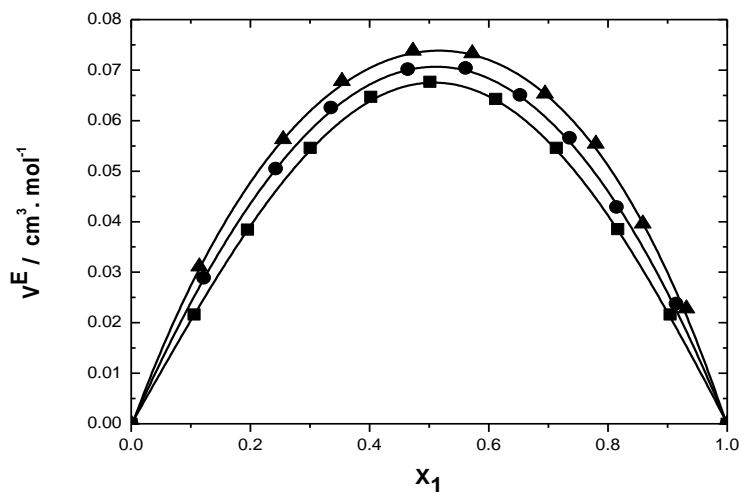

Figure 1 Variation of excess molar volume $\left(V^{E}\right)$ with mole fraction $\left(\mathrm{x}_{1}\right)$ of $\mathrm{N}, \mathrm{N}$-diethyl aniline in the binary liquid mixtures of N,N-diethyl aniline with 1-hexanol (•), 1-heptanol $(\bullet)$ and 1-octanol $(\boldsymbol{\Delta})$ at $303.15 \mathrm{~K}$

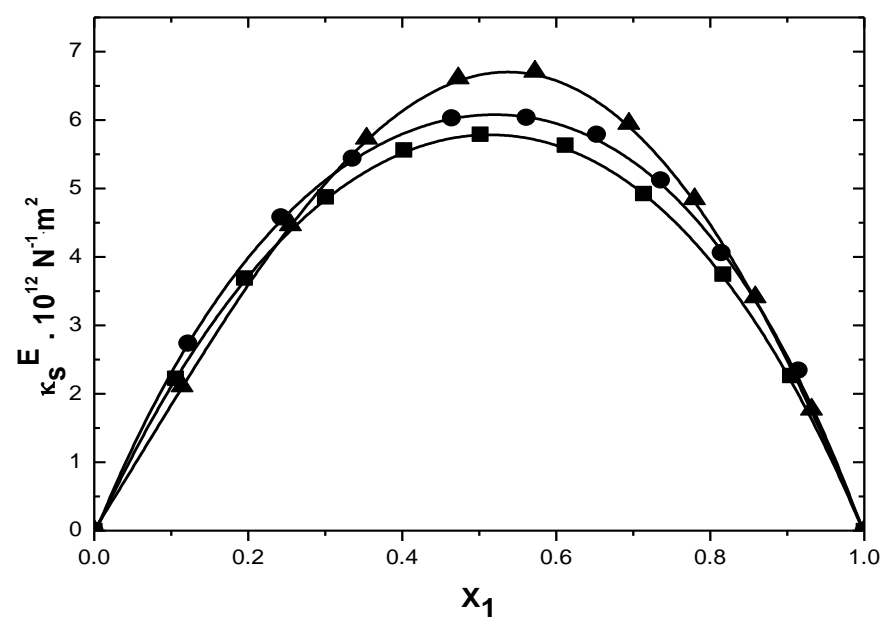

Figure 2 Excess isentropic compressibility $\left(\kappa_{\mathrm{s}}^{\mathrm{E}}\right)$ with mole fraction $\left(\mathrm{x}_{1}\right)$ of $\mathrm{N}, \mathrm{N}$-diethyl aniline in the binary

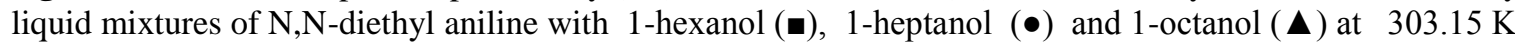

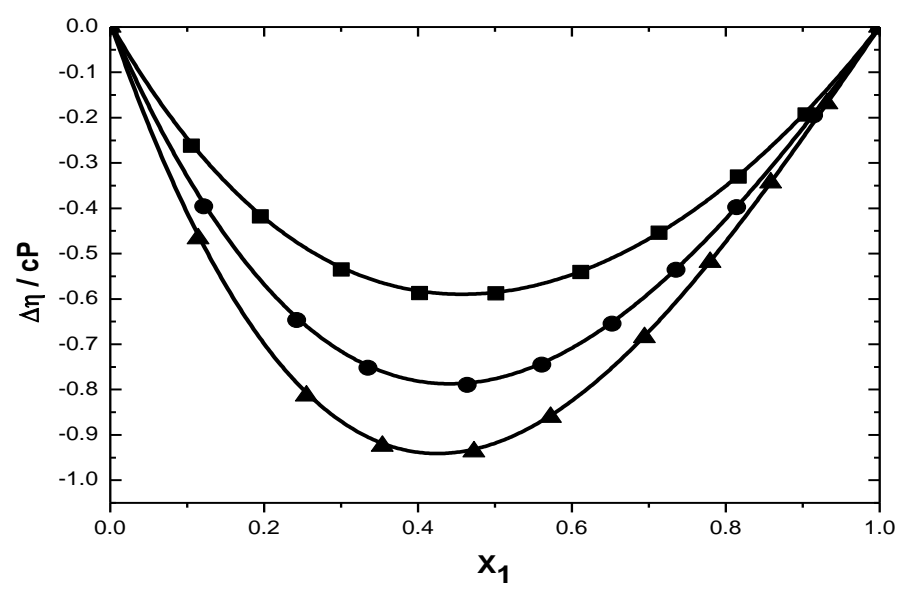

Figure 3 Variation of deviation viscosity $(\Delta \eta)$ with mole fraction $\left(\mathrm{x}_{1}\right)$ of $\mathrm{N}, \mathrm{N}$-diethyl aniline in the binary liquid mixtures of N,N-diethyl aniline with 1-hexanol (•), 1- heptanol (•) and 1-octanol $(\mathbf{\Lambda})$ at $303.15 \mathrm{~K}$ 


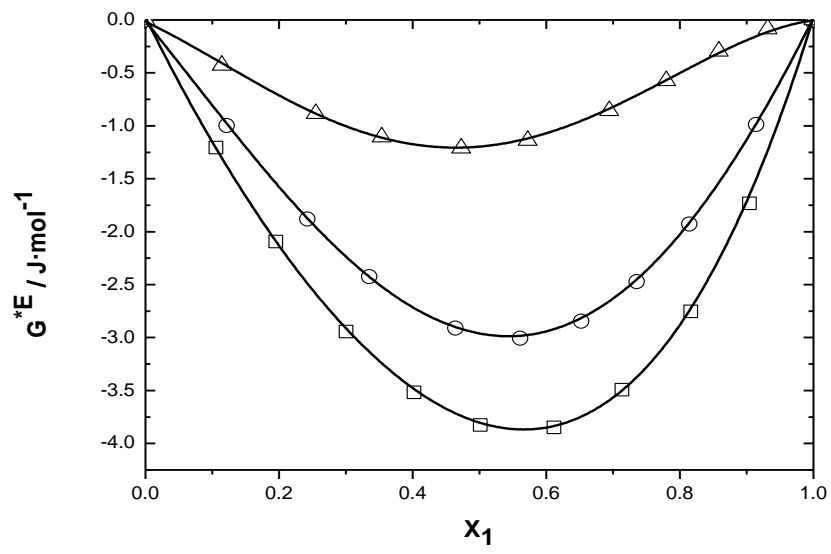

Figure 4 Excess Gibbs energy of activation of viscous flow $\left(G^{*} E\right)$ with mole fraction $\left(\mathrm{x}_{1}\right)$ of $\mathrm{N}, \mathrm{N}$-diethyl aniline in the binary liquid mixtures of $\mathrm{N}, \mathrm{N}$-diethyl aniline with 1-hexanol $(\forall), 1$-heptanol $(-)$ and 1-octanol $(\Delta)$ at $303.15 \mathrm{~K}$

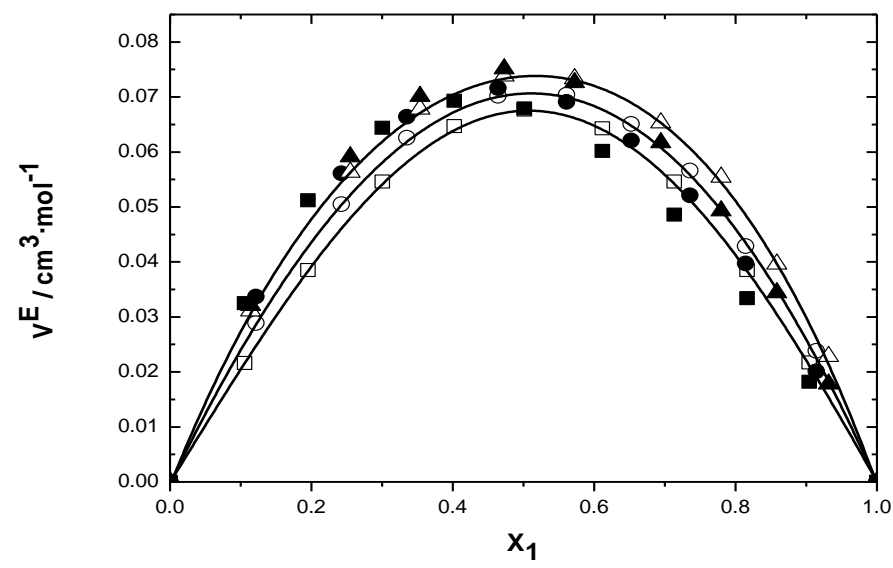

Figure 5 Excess molar volumes of the binary mixtures against mole fraction $\mathrm{x}_{1}$ at $\mathrm{T}=303.15 \mathrm{~K}$ for $\mathrm{N}, \mathrm{N}$ diethyl aniline + 1-hexanol $(\forall), \mathrm{N}, \mathrm{N}$-diethyl aniline + 1-heptanol $(-)$, N, N-diethyl aniline + 1-octanol $(\Delta)$ and (---) calculated with PFP theory using Parameters

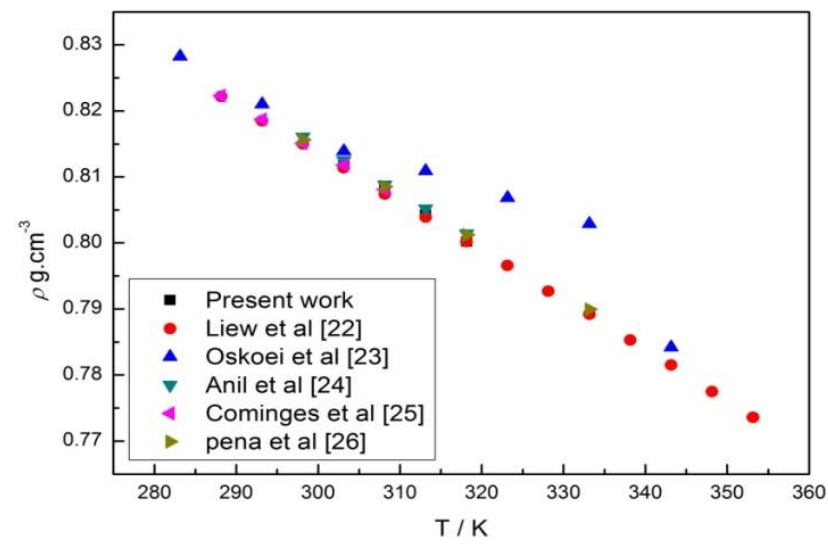

Figure1sdensity of 1-hexanol 


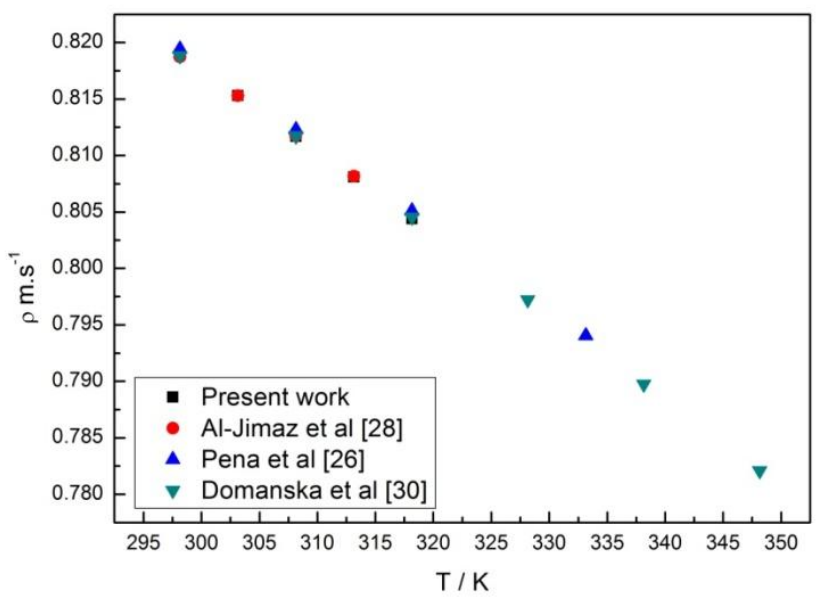

Figure2sdensity of 1-heptanol

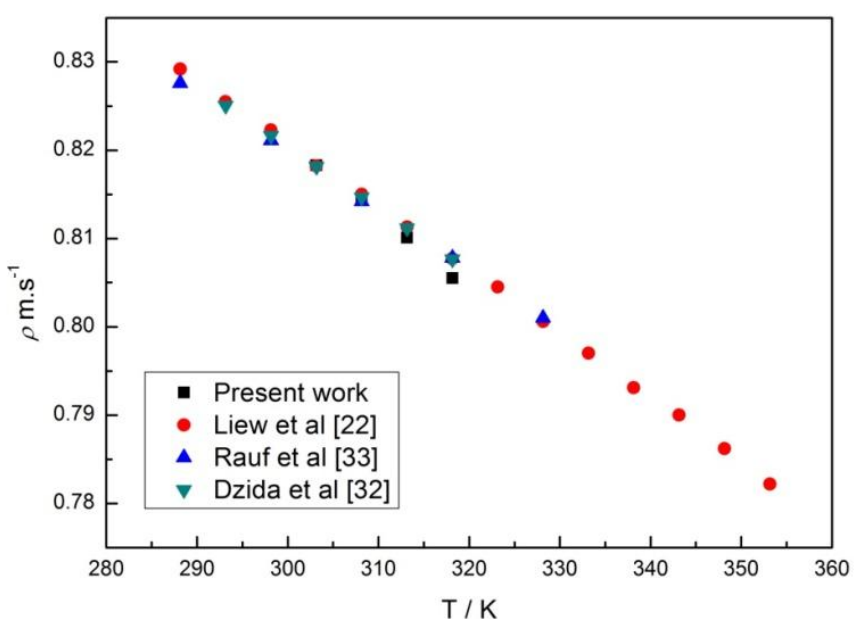

Figure 3sdensity of 1-octanol

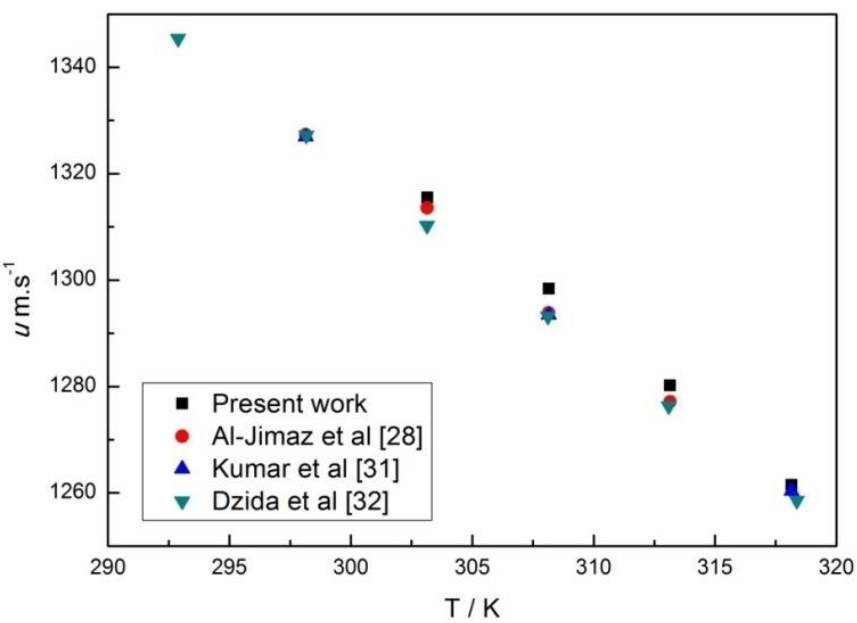

Figure 4sSpeed of sound of 1-hexanol 


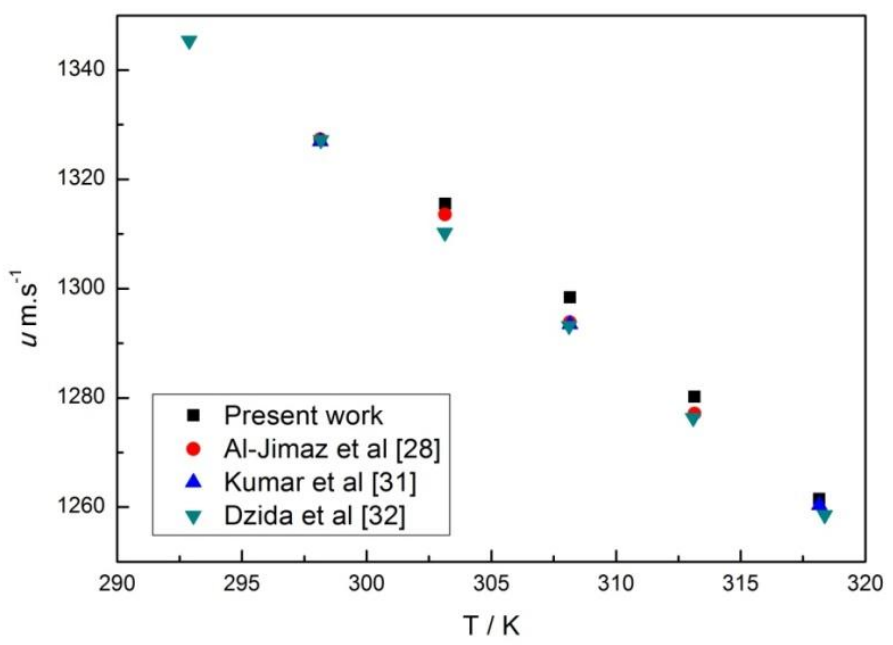

Figure 5sSpeed of sound of 1-heptanol

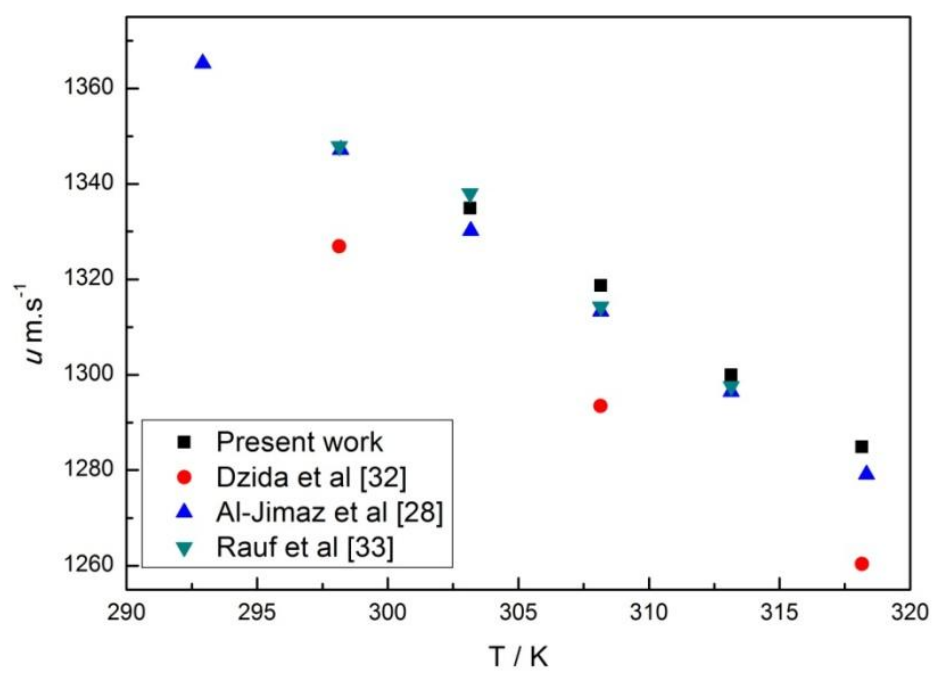

Figure6sSpeed of sound of 1-octanol

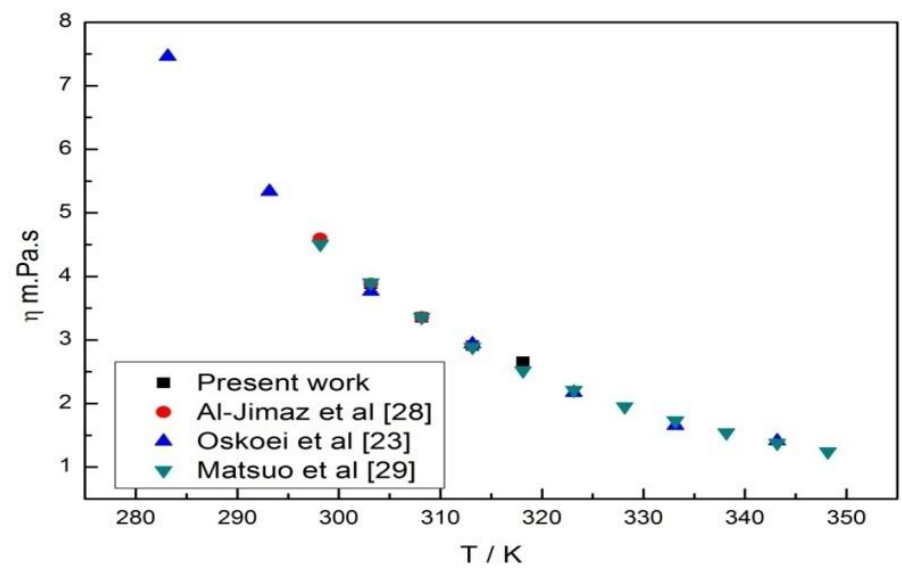

Figure 7s Viscosity of 1-hexanol 


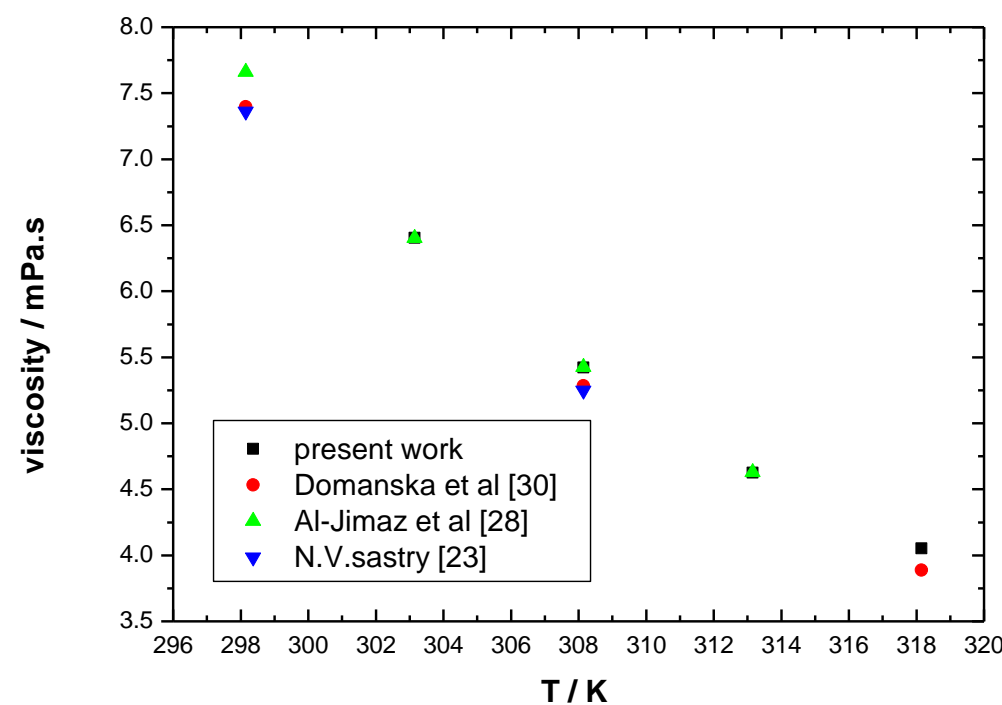

Figure 8s Viscosity of 1-heptanol

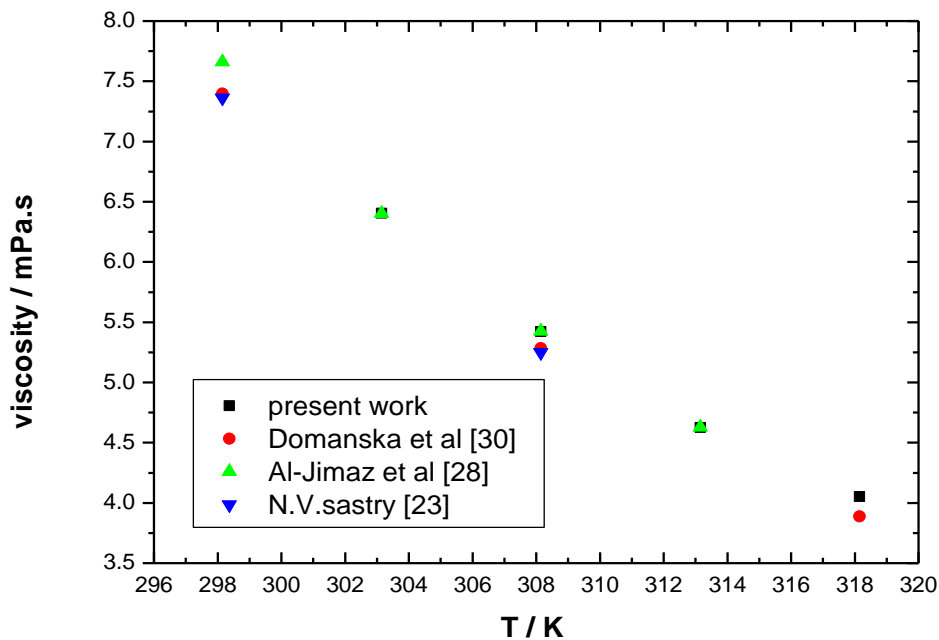

Figure 9sViscosity of 1-octanol

Table 1S: Coefficients of the polynomial for the correlation of the viscosity as a function of concentration at different temperatures for the N,N-diethylaniline (1) +1-heptanol (2), N,N-diethylaniline (1) +1-octanol (2)

Parameters of the equation $u=b_{3} x_{1}^{3}+b_{2} x_{1}^{2}+b_{1} x_{1}+b_{0}$ 
Electron releasing effect on the thermodynamic and transport properties of liquid mixtures at

Table 2S: Coefficients of the polynomial for the correlation of the speed of sound as a function of concentration at different temperatures for the N,N-diethylaniline (1) +1-octanol (2) binary system

\begin{tabular}{ccccc}
\hline$T /(\mathrm{K})$ & $b_{0} /\left(\mathrm{m} \cdot \mathrm{s}^{-1}\right)$ & $b_{1} /\left(\mathrm{m} \cdot \mathrm{s}^{-1}\right)$ & $b_{2} /\left(\mathrm{m} \cdot \mathrm{s}^{-1}\right)$ & $b_{3} /\left(\mathrm{m} \cdot \mathrm{s}^{-1}\right)$ \\
\hline 303.15 & 1334.73 & 38.91 & 17.13 & 41.55 \\
308.15 & 1318.02 & 24.70 & 50.51 & 0.471 \\
313.15 & 1298.85 & 13.90 & 72.33 & 0.642 \\
318.15 & 1284.31 & 35.19 & 14.71 & 11.47 \\
\end{tabular}

Parameters of the equation $u=b_{3} x_{1}^{3}+b_{2} x_{1}^{2}+b_{1} x_{1}+b_{0}$

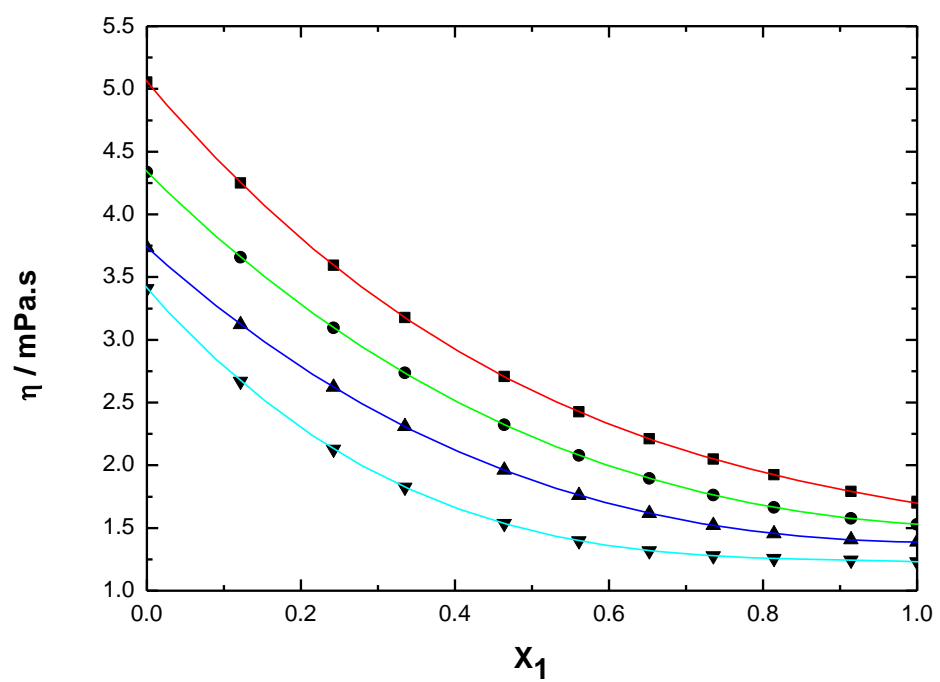

Figure10s: viscosity of binary mixture of N,N-diethylaniline+1-heptanol following the third-order polynomial equation

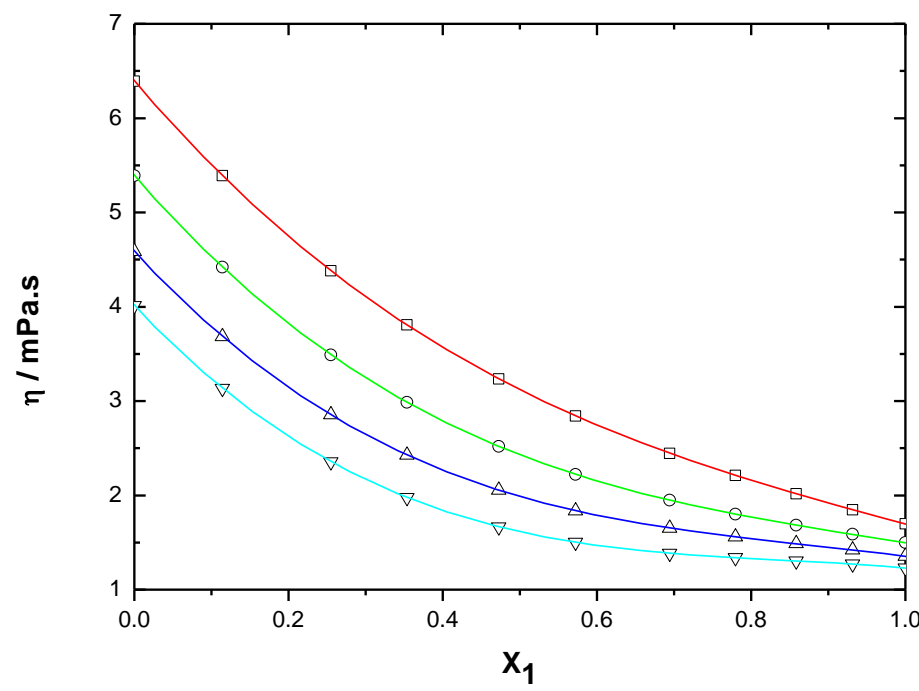

Figure11s: viscosity of binary mixture of N,N-diethylaniline+1-octanol following the third-order polynomial equation 


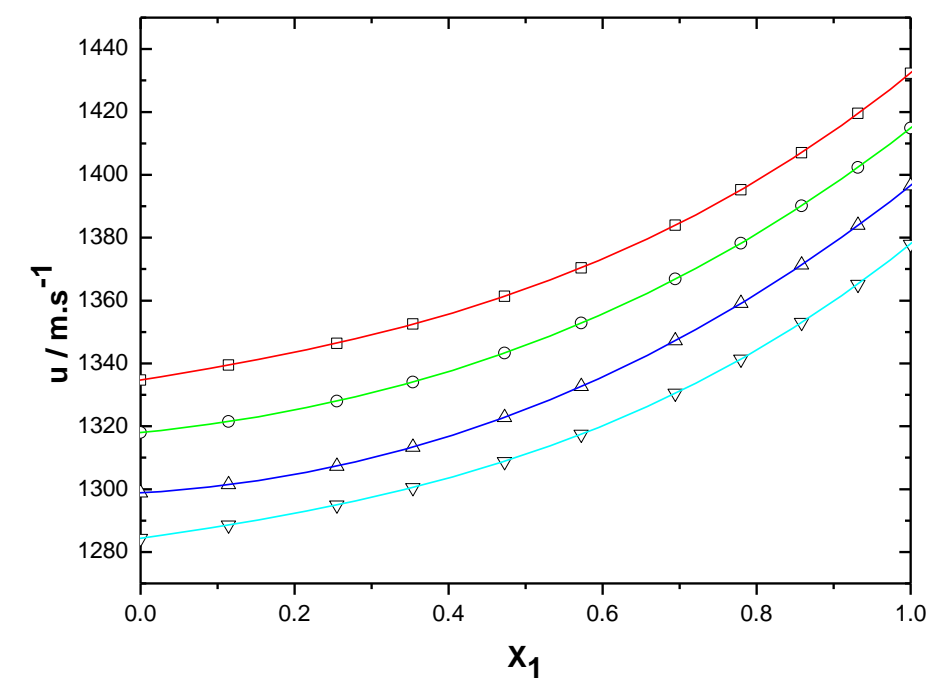

Figure12s: speed of sound of binary mixture of N,N-diethylaniline+1-octanol following the third-order polynomial equation

IOSR Journal of Applied Chemistry (IOSR-JAC) is UGC approved Journal with Sl. No. 4031, Journal no. 44190.

Muvva Raghavendra. "Electron Releasing Effect on the Thermodynamic and Transport Properties of Liquid Mixtures at Various Temperatures." IOSR Journal of Applied Chemistry (IOSR-JAC) 10.7 (2017): 12-27. 